\title{
Multi-target design strategies for the improved treatment of
}

\author{
Alzheimer's disease \\ Pengfei Zhang ${ }^{\text {a }}$, Shengtao $\mathrm{Xu}^{\mathrm{a}, *}$, Zheying $\mathrm{Zhu}{ }^{\mathrm{b}}$ and Jinyi $\mathrm{Xu}{ }^{\mathrm{a}, *}$

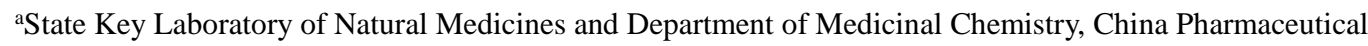 \\ University, 24 Tong Jia Xiang, Nanjing 210009, P. R. China \\ bDivision of Molecular Therapeutics \& Formulation, School of Pharmacy, The University of Nottingham, \\ University Park Campus, Nottingham NG7 2RD, U.K. \\ *Authors for correspondence: cpuxst@163.com,jinyixu@china.com
}

\begin{abstract}
Alzheimer's disease (AD) is a multifactorial syndrome resulting in profound misery and poses a substantial burden on human health, economy, and society throughout the world. Based on the numerous AD-related targets in the disease network, multi-target design strategy is a crucial direction to seek for enhanced therapy, and multi-target drugs have the ability to regulate more targets than single-target drugs, affecting the disease network with more potency. Herein, we highlight nine major targets associated with $\mathrm{AD}$, which are acetylcholine esterase (AChE), beta-site amyloid precursor protein cleaving enzyme 1 ( $\beta$-secretase, BACE-1), glycogen synthase kinase 3 beta (GSK-3 $\beta$ ), monoamine oxidases (MAOs), metal ions in the brain, $N$-methyl-D-aspartate (NMDA) receptor, 5-hydroxytryptamine (5-HT) receptors, the third subtype of histamine receptor $\left(\mathrm{H}_{3}\right.$ receptor), and phosphodiesterases (PDEs), and their respective relationship to the disease network. Furthermore, eleven multi-target design strategies classified by the involvement of $\mathrm{AChE}$ and related promising compounds for improved therapy of $\mathrm{AD}$ in recent years are described based on the nine major targets.
\end{abstract}

Keywords: Alzheimer's disease, multi-target strategy, acetylcholine esterase, donepezil, tacrine

\section{Contents:}

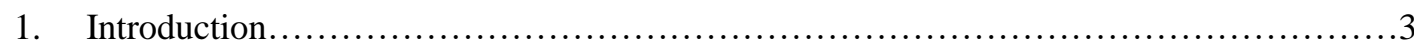

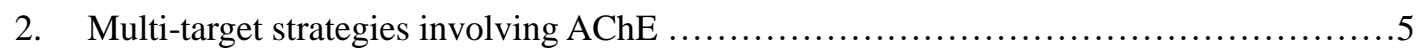

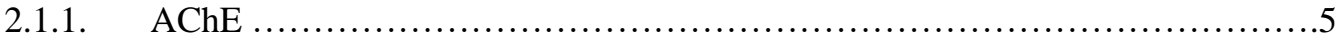




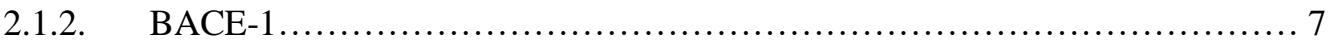

2.1.3. AChE and BACE-1 multi-target strategy ................................. 9

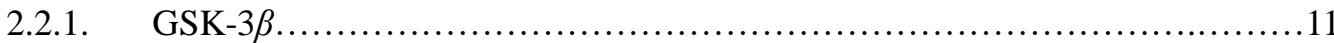

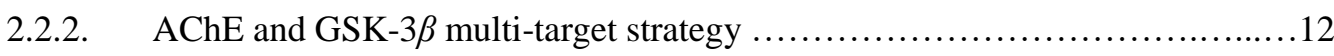

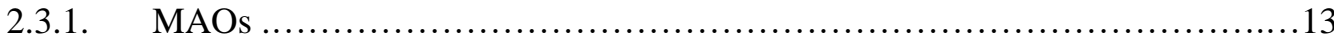

2.3.2. AChE and MAOs multi-target strategy ................................... 14

2.4.1. Metal ions in the brain ................................................... 17

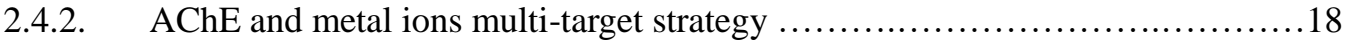

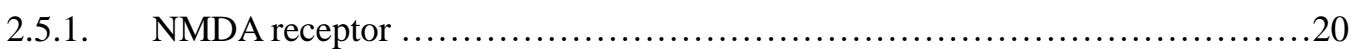

2.5.2. AChE and NMDA receptor multi-target strategy ...........................21

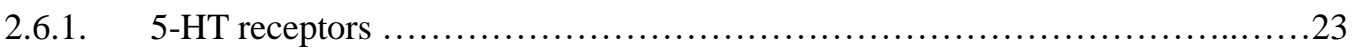

2.6.2. AChE and 5-HT receptors multi-target strategy ........................... 24

2.7.1. Histamine receptors ................................................... 25

2.7.2. $\quad \mathrm{AChE}$ and $\mathrm{H}_{3}$ receptor multi-target strategy ............................. 26

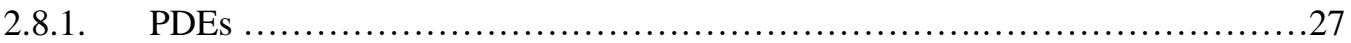

2.8.2. AChE and PDEs multi-target strategy .................................... 28

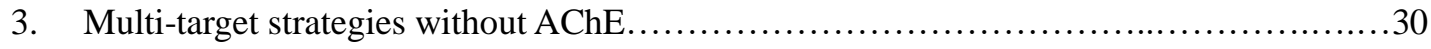

3.1. BACE-1 and GSK-3 $\beta$ multi-target strategy ................................ 30

3.2. MAO-B and metal ions multi-target strategy ................................ 31

3.3. PDEs and metal ions multi-target strategy ................................. 32

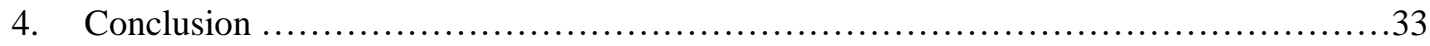

Acknowledgements............................................................ 34

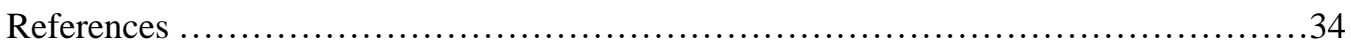

\section{Abbreviations:}

$\mathrm{ACh}$

AChE

AChEI

$\mathrm{AD}$

APP

$\mathrm{A} \beta$

BACE-1
Acetylcholine

Acetylcholine esterase

AChE inhibitor

Alzheimer's disease

Amyloid precursor protein

beta-amyloid

beta-site amyloid precursor protein cleaving enzyme 1 


\begin{tabular}{|c|c|}
\hline BBB & Blood-brain barrier \\
\hline $\mathrm{BChE}$ & Butyrylcholinesterase \\
\hline cAMP & Cyclic adenosine monophosphate \\
\hline cGMP & Cyclic guanosine monophosphate \\
\hline $\mathrm{ChE}$ & Cholinesterase \\
\hline CNS & Central nervous system \\
\hline $\mathrm{COX}$ & Cyclooxygenase \\
\hline CREB & cAMP response element-binding protein \\
\hline $\mathrm{EC}_{50}$ & Concentration for $50 \%$ of maximal effect \\
\hline ED & Erectile dysfunction \\
\hline Gly & Glycine \\
\hline GSK- $3 \beta$ & Glycogen synthase kinase 3 beta \\
\hline HT & Hydroxytryptamine \\
\hline $\mathrm{IC}_{50}$ & Half maximal inhibitory concentration \\
\hline $\mathrm{K}_{\mathrm{i}}$ & Inhibition constant \\
\hline LOX & Lipoxygenase \\
\hline MAO & Monoamine oxidase \\
\hline MCI & Mild cognitive impairment \\
\hline MD & Myotonic dystrophy \\
\hline MMSE & Mini-Mental State Examination \\
\hline MTDL & Multi-target-directed ligand \\
\hline NCE & New chemical entity \\
\hline NFT & Neurofibrillary tangle \\
\hline NMDA & $N$-methyl-D-aspartate \\
\hline $\mathrm{NO} / \mathrm{sGC} / \mathrm{cGMP}$ & The nitric oxide/soluble guanylyl cyclase/cGMP \\
\hline NQO1 & NAD(P)H:quinone oxidoreductase 1 \\
\hline ORAC & Oxygen radical absorbance capacity \\
\hline PAMPA & The parallel artificial membrane permeation assay \\
\hline PD & Parkinson disease \\
\hline PDE & Phosphodiesterase \\
\hline ROS & Reactive oxygen species \\
\hline sAPP- $\alpha$ & Soluble amyloid precursor protein $\alpha$ \\
\hline SGZ & Subgranular zone \\
\hline SSRI & Selective serotonin reuptake inhibitor \\
\hline
\end{tabular}

\section{Introduction}

$\mathrm{AD}$ is an progressive neurodegenerative disorder associated with the appearance of extracellular senile or neuritic plaques and intracellular neurofibrillary tangles in the brain [1] that induce memory loss and cognition impairment, causing enormous suffering to individuals, families, and society [2]. AD was first reported by Alois Alzheimer in 1907 [3] and is now deemed by World Health Organization as the most common cause of dementia, with approximately 47 million 
patients worldwide in 2018, and is estimated to affect 75 million people by 2030 and 140 million people by 2050 globally [4]. The nebulous and complicated pathogenesis of AD makes it difficult to develop new drugs, and also leads to failure of many promising drug candidates when tested in clinical trials with the result of unpredictable clinical manifestations. Despite these challenges, research of $\mathrm{AD}$ is still a hot topic, and the efforts and attempts of scientific groups worldwide are continuing, with the aim of finding an effective treatment [5].

Currently, exploration of $\mathrm{AD}$ has led to the discovery of many primary targets that influence generation and exacerbation of the disease, such as AChE, BACE-1, GSK-3 $\beta$, MAOs, metal ions in the brain, NMDA receptor, 5-HT receptors, $\mathrm{H}_{3}$ receptor, and PDEs (Figure 1). And lots of potent and effective compounds for the treatment of $\mathrm{AD}$ are discovered based on these targets, among which donepezil (1), galantamine (2), rivastigmine (3), and memantine (14) (Table 1) (Figure 2) are the only four drugs approved by the FDA for the treatment of AD. And all of them are single-target drugs that can notably improve the conditions of patients in cognition deterioration and memory loss, but these drugs cannot completely cure the disease. It is a unique and intricate feature of $\mathrm{AD}$ that relevant targets in different cell signaling pathways can interact with each other and form a disease network, and this results in a poor curative effect of single-

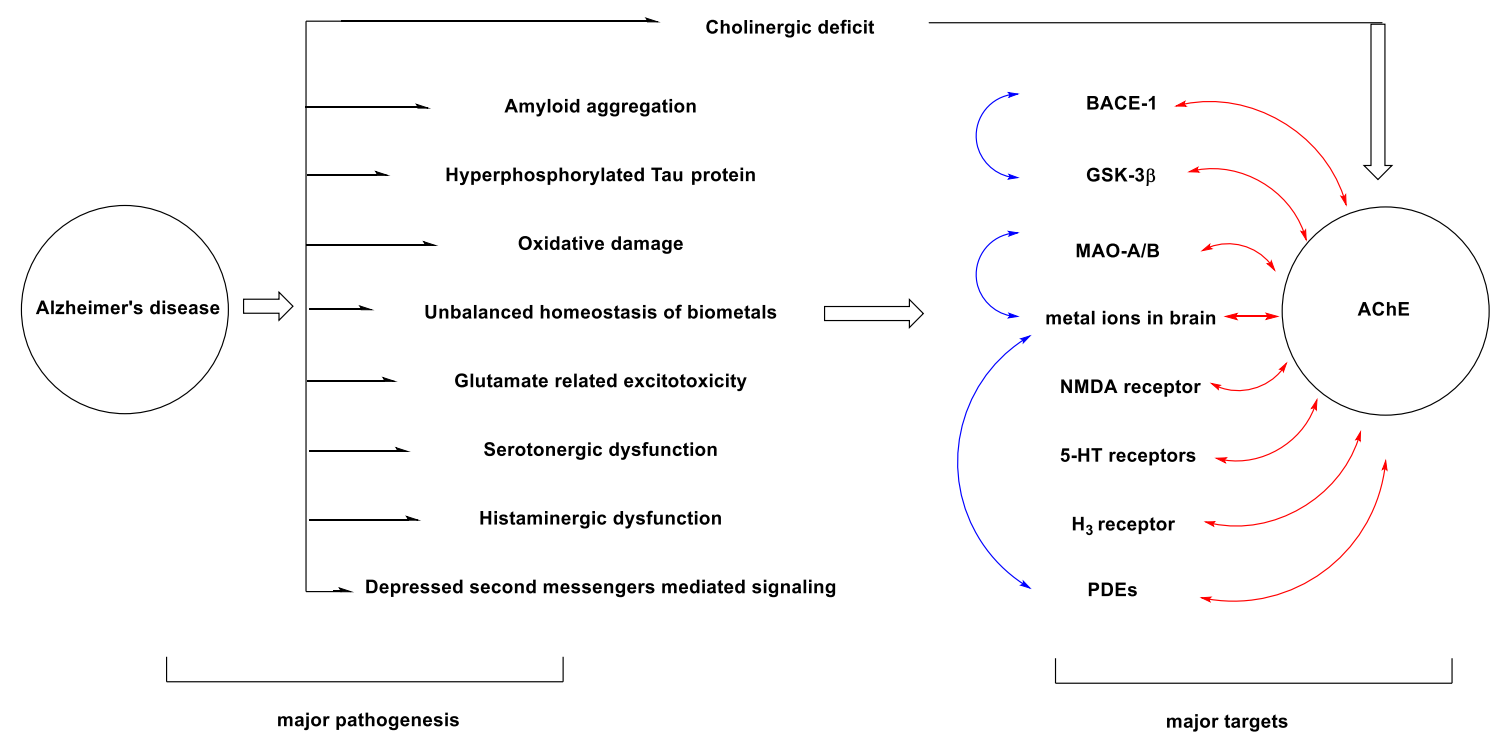

Figure 1. Concise relationships between $\mathrm{AD}$ and nine major targets, and eleven multi-target design strategies based on the targets. Red lines: multi-target strategies involving AChE. Blue lines: multi-target strategies without AChE involvement. 
target drugs. Based on the complicated pathogenesis of $\mathrm{AD}$ and the imperfect single-target drugs, multi-target strategies are becoming more and more popular for potential treatment of AD because several targets associated with AD could be affected by one multi-target drug, which can have a synergistic effect on the disease network, leading to better improvement on memory and cognition. Therefore, multi-target design strategy for AD therapy is an important direction in current research compared with single-target drugs, and multi-target drugs will likely be more pivotal and effective in regulating disease progression.

\section{Multi-target strategies involving AChE}

Nine related targets in $\mathrm{AD}$ are presented in this section, which are AChE, BACE-1, GSK-3 $\beta$, MAOs, metal ions in the brain, NMDA receptor, 5-HT receptors, $\mathrm{H}_{3}$ receptor, and PDEs. These nine targets and their respective signaling pathways could influence the disease progression by themselves and interactions among them, also resulting in the complicated and unclear disease network of $\mathrm{AD}$. Among them, $\mathrm{AChE}$ is the most pivotal target of the well-known $\mathrm{AD}$ network, and multi-target drugs are designed to involve this target to increase the availability and decrease the failure risk of new chemical entities (NCEs). In short, AChE is the most popular target in AD-related targets and multi-target design strategy involving $\mathrm{AChE}$ is the most popular strategy in $\mathrm{AD}$-related multi-target strategies. In this section, eight multi-target strategies involving AChE and related targets are reviewed (Figure 1).

\subsubsection{AChE}

The cholinergic hypothesis, a significant guidance orientation of $\mathrm{AD}$, was first reported by Davies and Maloney in 1976 [6], states that the reduction of acetylcholine (ACh) in presynaptic cholinergic terminals of the hippocampus and the neocortex regions caused by degeneration of cholinergic neurons of basal forebrain nuclei plays a key role in AD pathology, and the conclusive treatment is to up-regulate the ACh concentration in the synaptic cleft [7]. ACh in the synaptic cleft is secreted by synaptic vesicles to activate muscarinic and nicotinic receptors and is immediately decomposed to choline and acetate [8] by AChE under normal physiological conditions. AChE is a highly kinetically efficient enzyme, and each AChE molecule can hydrolyze 5000 ACh molecules per second [9]. Butyrylcholinesterase (BChE) can also hydrolyze ACh, and its levels progressively rise in advancing $\mathrm{AD}$, while $\mathrm{AChE}$ activity remains unchanged or declines 
[10]. $\mathrm{BChE}$ is becoming an interesting target because selective $\mathrm{BChE}$ inhibitors have displayed amyloid-lowering activity which is a useful effect to improve dementia condition [11]. Highly selective $\mathrm{BChE}$ inhibitors or dual $\mathrm{AChE}$ and $\mathrm{BChE}$ inhibitors represent another new potential approach for $\mathrm{AD}$ treatment; however, this multi-target strategy is not discussed in this article

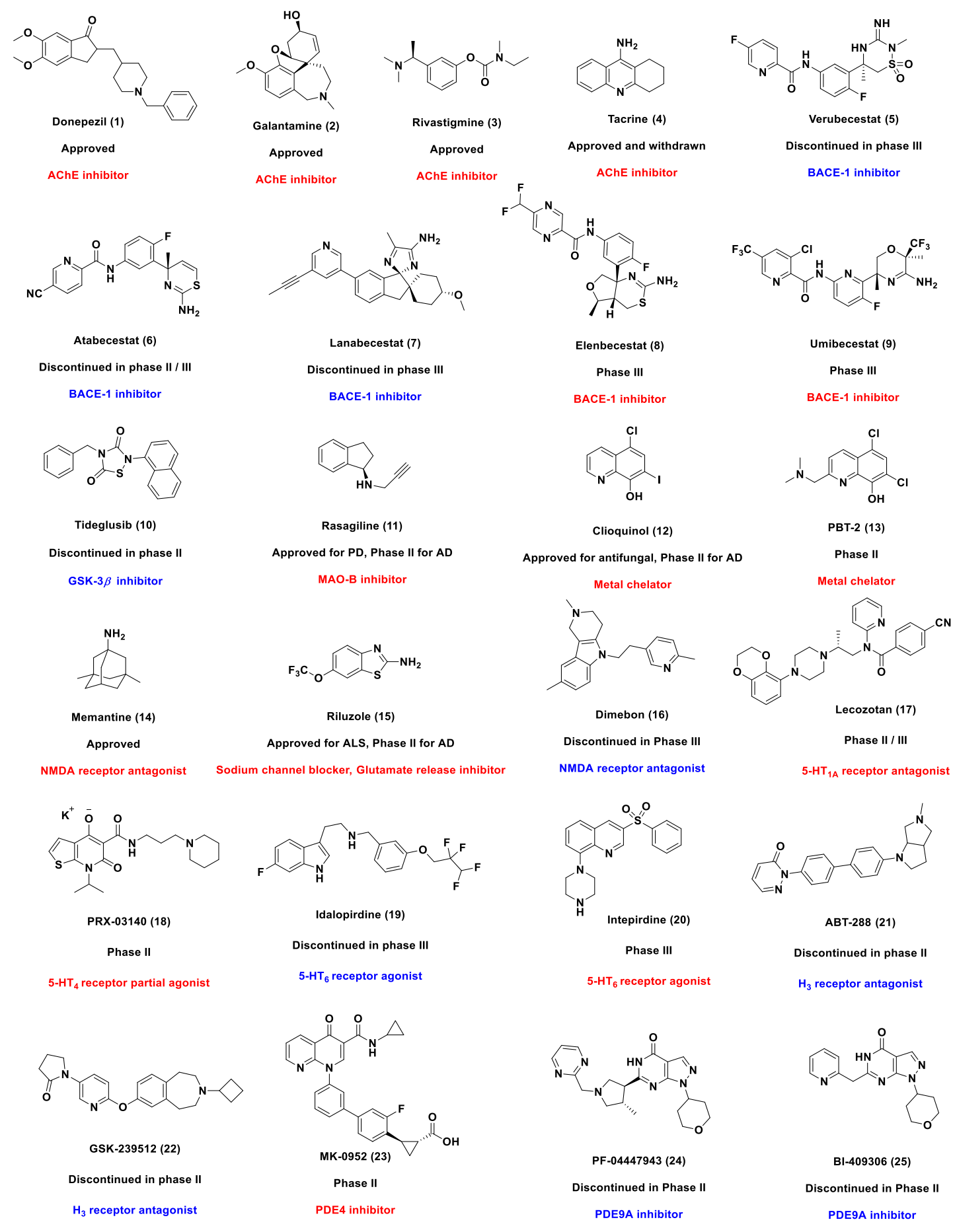

Figure 2. Related single-target drugs that are approved or in clinical trials for the treatment of AD. Red refers to the approved drugs or candidates in clinical trials, and blue refers to the discontinued candidates in clinical trials. 
because of the unclear theoretical basis of $\mathrm{BChE}$ and the close relationship between the two targets [12].

Inhibition of AChE activity to prevent degradation of ACh in synapses is the most primary method in medicinal chemistry, which makes AChE a vital target and leads the inhibition activity of $\mathrm{AChE}$ to be a fundamental evaluation criterion. The present clinical drugs approved by the FDA are principally AChE inhibitors (AChEIs), such as donepezil (1), galantamine (2), and rivastigmine (3) [13] (Table 1) (Figure 2), which can notably slow down memory loss and improve the cognition function of patients, while dementia cannot be prevented or completely cured by them [14]. Tacrine (4) (Figure 2) was approved in 1993 as the first AChEI for AD treatment and was withdrawn shortly after due to liver toxicity [2], but its structure is still important for the new drug design. Donepezil (1) (Figure 2) of Eisai and Pfizer, the top-selling AChEI drug worldwide among AD-related clinical drugs, was approved in 1997 for the treatment of mild-to-moderate AD, and was approved in 2014 for additional treatment of Lewy body dementia. Donepezil (1) is available as disintegrating tablets or oral solutions to be administered at a dose of 5-10 mg once a day due to its long half-life, with a starting dose of $5 \mathrm{mg} /$ day. Donepezil (1) is a safe and well tolerated drug based on current clinical evidence, it can improve cognition and shows clinical amelioration in overall functioning even for patients with severe $\mathrm{AD}$ [14]. Tacrine (4) and donepezil (1) are still subjected to various modifications by research groups [15], and are often used as positive controls in enzyme activity tests in vitro and in pharmacological experiments with AD-related animal models in vivo to test the AChE inhibitory potency and safety of NCEs. The cholinergic hypothesis and approved drugs make AChE and AChEIs a high profile in AD field, lead single-target strategy aiming at $\mathrm{AChE}$ and multi-target strategy involving $\mathrm{AChE}$ to become common thoughts in new drug design for the potential treatment of AD.

\subsubsection{BACE-1}

The amyloid hypothesis, a currently popular theoretical foundation first outlined by Hardy and Higgins in 1992 [16], states that the production, oligomerization and self-aggregation of beta-amyloid ( $\mathrm{A} \beta$ ) cause synaptic dysfunction and senile plaques which is the typical hallmark of $\mathrm{AD}$ [17]. The degradation of major amyloid precursor protein (APP) occurs through a two-step proteolysis reaction catalyzed by $\alpha$-secretase and $\gamma$-secretase with no physical damage [18], while 
a small proportion of APP is degraded by $\beta$-secretase (BACE-1) and $\gamma$-secretase to generate A $\beta$ which is composed of 37-49 amino acid residues and mainly shown as $\mathrm{A} \beta_{40}$ and $\mathrm{A} \beta_{42}$ peptides [19]. $\mathrm{A} \beta_{40}$ is the more common metabolite and may actually be anti-amyloidogenic, whereas $\mathrm{A} \beta_{42}$ and longer peptides are highly self-aggregating and lead to profound $\mathrm{A} \beta$ deposition [20].

Table1. Fundamental information regarding four drugs which have been approved by the FDA for the treatment of $\mathrm{AD}$

\begin{tabular}{|c|c|c|c|c|}
\hline Drug & Donepezil (1) & Galantamine (2) & Rivastigmine (3) & Memantine (14) \\
\hline Salt type & Hydrochloride & Hydrobromide & Tartrate & Hydrochloride \\
\hline $\begin{array}{l}\text { Launch year for } \\
\qquad \mathrm{AD}\end{array}$ & 1997 & 1995 & 1997 & 2002 \\
\hline Brand name & Aricept & Reminyl & Exelon & Ebixa \\
\hline Indication of $\mathrm{AD}$ & Mild to moderate & Mild to moderate & Mild to moderate & Moderate to severe \\
\hline Mode of action & $\begin{array}{l}\text { Selective AChE } \\
\text { inhibition }\end{array}$ & $\begin{array}{l}\text { Selective AChE } \\
\text { inhibition }\end{array}$ & $\begin{array}{l}\text { Slowly reversible } \\
\text { AChE and BChE } \\
\text { inhibition }\end{array}$ & $\begin{array}{c}\text { Non-competitive } \\
\text { NMDA-receptor } \\
\text { antagonist }\end{array}$ \\
\hline Half-life [1] & $70 \mathrm{~h}$ & $7-8 \mathrm{~h}$ & $1 \mathrm{~h}$ & $60-100 \mathrm{~h}$ \\
\hline Metabolism [14] & $\begin{array}{c}\text { CYP2D6 and } \\
\text { CYP3A4 in liver }\end{array}$ & $\begin{array}{c}\text { CYP2D6 and } \\
\text { CYP3A4 in liver }\end{array}$ & $\mathrm{AChE}$ & Kidney \\
\hline Given with food & Irrelevant & Recommended & Yes & Irrelevant \\
\hline $\begin{array}{c}\text { Clinically efficient } \\
\text { dose }\end{array}$ & $5-10 \mathrm{mg} /$ day & $16-24 \mathrm{mg} /$ day & 6-12 mg/day & $20 \mathrm{mg} /$ day \\
\hline
\end{tabular}

Despite continuing arguments for the amyloid hypothesis [18], the growing consensus is that anti-amyloid drugs will be most effective in the early AD process [21]. Obviously, BACE-1 is the most suitable target to decrease $\mathrm{A} \beta$ production in the APP metabolic pathway by inhibiting its activity, and mice with BACE-1 deficiency showed a healthy and fertile clinical phenotype with abolished $\mathrm{A} \beta$ production in the brain [22], making BACE-1 a popular target and its inhibitors an attractive therapeutic strategy. The clinical situation of BACE-1 inhibitors is cruel (Figure 2). The drug verubecestat (5) of Merck in Phase III was discontinued in February 2017 due to lack of 
efficacy [23, 24]. The Phase II/III drug atabecestat (6) of Johnson \& Johnson was discontinued in May 2018 for the increase of hepatic enzyme, and the Phase III drug lanabecestat (7) of Eli Lilly and AstraZeneca was discontinued in June 2018 because no curative endpoint was achieved. The optimistic cases of BACE-1 inhibitors are that the drug LY3202626 (structure not disclosed) from Eli Lilly is in Phase II clinical trials, the drug elenbecestat (8) from Biogen and Eisai is in Phase III clinical trials [25], and the drug umibecestat (9) from Novartis and Amgen is in Phase III clinical trials.

\subsubsection{AChE and BACE-1 multi-target strategy}

Design of multi-target NCEs based on AChEI drugs, such as donepezil (1) and tacrine (4), is popular because the scaffolds of approved drugs with evident AChE inhibition capacity can hopefully guarantee the efficacy of new compounds, at least for targeting AChE, reducing the failure risk of developing new drugs. Combining the pharmacophores of AChEI drugs and BACE-1 inhibitors with a suitable linker is a common approach to design novel dual inhibitors targeting both enzymes.

Zhu and co-workers [26] reported a series of hybrid compounds with AChE and BACE-1 dual inhibitions, and the scaffold was fused through three types of linkers with AChEI donepezil (1) and isophthalamide (26), a widely used pharmacophore in BACE-1 inhibitors [27]. Among these compounds, hybrid 27 (Figure 3) was considered as the most potential multi-target agent for therapeutic application of $\mathrm{AD}$, and showed excellent dual inhibition in enzyme inhibitory potency assay $\left(\mathrm{IC}_{50}=1.83 \mu \mathrm{M}\right.$ for $\mathrm{AChE}, \mathrm{IC}_{50}=0.567 \mu \mathrm{M}$ for BACE-1), good inhibitory effects on $\mathrm{A} \beta$ production in APP-transfected HEK293 cells $\left(\mathrm{IC}_{50}=98.7 \mathrm{nM}\right)$, and a mild antioxidative effect against $\mathrm{H}_{2} \mathrm{O}_{2}$-induced PC12 cell injury at $10 \mu \mathrm{M}$. Further in vivo experiments in APP transgenic mice showed that compound 27 caused a $29 \%$ reduction in $\mathrm{A} \beta_{1-40}$ production through intracerebroventricular administration. Another compound, hybrid 28 (Figure 3), reported by the Praveen group [28], was fused with donepezil (1) and 2,4-disubstituted pyrimidine, a template with an $\mathrm{A} \beta$-aggregation inhibition profile [29], and showed dual inhibitory activities in the enzyme assay ( $\mathrm{IC}_{50}=9.9 \mu \mathrm{M}$ for $\mathrm{AChE}, 34 \%$ inhibition at $10 \mu \mathrm{M}$ for BACE-1), $17.4 \%$ self-induced $\mathrm{A} \beta_{1-40}$ aggregation inhibition at $100 \mu \mathrm{M}$, and $81.0 \%$ neuroblastoma cell viability at $40 \mu \mathrm{M}$.

Fernandez-Bachiller and co-workers [30] reported a new family of AChEI tacrine (4) and 4-oxo-4H-chromene (29) hybrids, in which the tacrine (4) scaffold was selected for AChE 
inhibition and a flavonoid fragment derived from 4-oxo-4H-chromene (29) was chosen for BACE-1 inhibition. The most promising compound, hybrid 30 (Figure 3), showed potent dual inhibition against human $\mathrm{AChE}$ and $\mathrm{BACE}-1\left(\mathrm{IC}_{50}=8.0 \mathrm{nM}\right.$ for $\mathrm{AChE}, \mathrm{IC}_{50}=2.8 \mu \mathrm{M}$ for BACE-1), 1.3-fold more potent antioxidant activity than trolox (a vitamin E analogue), and good central nervous system (CNS) permeability in the parallel artificial membrane permeation assay for blood-brain barrier (PAMPA-BBB). A promising compound, hybrid 34 (Figure 3), reported by the Munoz-Torrero group [31], was fused through a long alkylamine linker with rhein (33) and huprine Y (32), another hybrid from tacrine (4) and huperzine A (31) [32], and showed potent inhibitory activities against human AChE and BACE-1 $\left(\mathrm{IC}_{50}=3.6 \mathrm{nM}\right.$ for AChE, $\mathrm{IC}_{50}=120 \mathrm{nM}$ for BACE-1) and $47.9 \% \mathrm{~A} \beta_{42}$ anti-aggregating activity at $10 \mu \mathrm{M}$. Further in vivo experiments in APP-PS1 transgenic mice showed a central soluble A $\beta$-lowering effect four weeks later after intraperitoneal administration with compound 34. Replacement of the chlorobenzene ring of the huprine Y (32) moiety of $\mathbf{3 4}$ with pyridine led to lower AChE and BACE-1 inhibitory activities but potent antioxidant activity [33]. Another potent tacrine (4)-benzofuran (35) hybrid 36 (Figure 3), reported by the Bartolini group [34], showed an interesting profile as a dual inhibitor against human AChE and BACE-1 ( $\mathrm{IC}_{50}=0.86 \mathrm{nM}$ for AChE, $\mathrm{IC}_{50}=1.35 \mu \mathrm{M}$ for BACE-1) and $61.3 \%$ inhibition toward self-induced $\mathrm{A} \beta$ aggregation at $10 \mu \mathrm{M}$. Further in vivo studies confirmed that 36 caused cognitive improvement in scopolamine-treated ICR mice and exhibited no significant hepatotoxicity.

Computer-aided structure-based design is a practical and efficient method to find new active hits. Dominguez and co-workers [35] reported that after two cycles of design and screening of candidates based on pharmacophores and required interactions with the targets, compound $\mathbf{3 7}$ (Figure 3) was discovered, synthesized, and showed evident dual inhibition activities against AChE and BACE-1 $\left(\mathrm{IC}_{50}=9.1 \mu \mathrm{M}\right.$ for AChE, $\mathrm{IC}_{50}=2.5 \mu \mathrm{M}$ for BACE-1). Innovating new compound scaffolds through the self-accumulated effort and knowledge of scientific groups is another classical drug discovery approach. Belluti and co-workers [36] reported that compound $\mathbf{3 8}$ (Figure 3) with a benzophenone core, showed dual-target inhibitory potency against human AChE and BACE-1 $\left(\mathrm{IC}_{50}=1.57 \mu \mathrm{M}\right.$ for AChE, $10.72 \%$ inhibition at $3.38 \mu \mathrm{M}$ for BACE-1). Recently, a new compound 39 (Figure 3) with a benzophenone core was reported by the Gabr group [37], showing potent human $\mathrm{AChE}$ and BACE-1 inhibition $\left(\mathrm{IC}_{50}=4.11 \mathrm{nM}\right.$ for $\mathrm{AChE}, \mathrm{IC}_{50}=18.3 \mathrm{nM}$ 
for BACE-1), potential metal chelating capability, low toxicity toward SH-SY5Y neuroblastoma cells, and the ability to permeate the BBB tested by PAMPA.
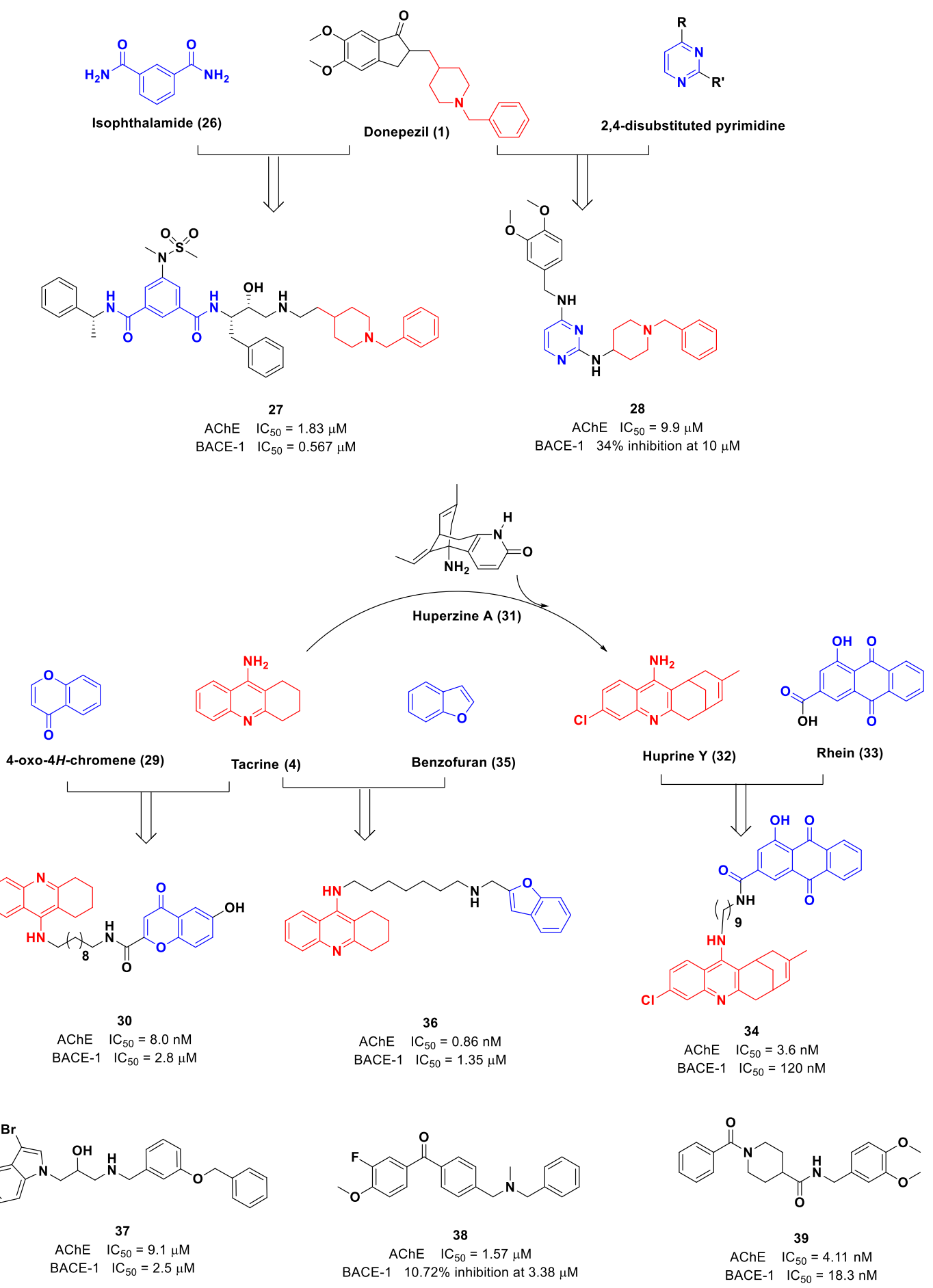

Figure 3. AChE and BACE-1 multi-target strategy

\subsubsection{GSK-3 $\beta$}

The tau protein hypothesis is based on intracellular neurofibrillary tangles (NFTs) in the brain 
which is another histopathological hallmark of AD just as senile plaques. NFTs are composed of paired helical filaments and straight filaments which are mainly caused by hyperphosphorylated tau protein [38]. The primary physiological function of tau protein, the most abundant microtubule-associated protein expressed in neurons, is to form microtubules with microtubule proteins, maintain microtubules stabilization, and promote microtubules to concentrate in clusters. When tau protein is hyperphosphorylated by the highly conserved threonine-serine kinase GSK-3 $\beta$, primarily at Ser396, Ser199, and Ser413 [39], from the original 2-3 phosphate groups to 5-9 phosphate groups, it is separated from microtubules and subsequently aggregated into insoluble NFTs which ultimately cause cell death [40]. Not only can GSK-3 $\beta$ phosphorylate tau protein, increased GSK- $3 \beta$ levels could regulate $\gamma$-secretase to induce $\mathrm{A} \beta$ formation in a unique way, resulting in toxicity to cultured neurons [41]. The three aspects of therapies based on the tau protein hypothesis include inhibiting the phosphorylation, preventing the aggregation of tau protein, and stabilizing microtubules, and GSK- $3 \beta$ is the major and specific target in the upstream tau pathway, making it the most popular target for small molecule compounds. The GSK-3 $\beta$ inhibitor tideglusib (10) (Figure 2) from AMO-pharma belongs to the thiadiazolidinone family and is currently in Phase II clinical trials for the treatment of myotonic dystrophy (MD). Tideglusib (10) was in Phase II clinical trials for the treatment of AD, but the trial was discontinued in 2012 due to a lack of drug efficacy, even though it showed positive trends in four out of five clinical scales and induced a significantly benign response on the Mini-Mental State Examination (MMSE) [42].

\subsubsection{AChE and GSK-3 $\beta$ multi-target strategy}

AChE and GSK-3 $\beta$, each of which has been frequently adopted in multi-target strategies, are two vital AD-related targets in ACh concentration modulation and tau protein phosphorylation, respectively. However multi-target-directed ligands (MTDLs) possessing inhibitory potency for both enzymes are rarely reported.

Hui and co-workers [43] reported that hybrid 41 (Figure 4), fused with the AChEI tacrine (4) and phenothiazine which is the key pharmacophore of the tau aggregation inhibitor methylene blue (40) (Figure 4), showed AChE inhibitory potency $\left(\mathrm{IC}_{50}=89 \mathrm{nM}\right)$. And tau hyperphosphorylation induced by okadaic acid in $\mathrm{N} 2 \alpha$ cells was markedly prevented by hybrid $\mathbf{4 1}$ with 39.5\% down-regulation of the tau protein level when $\mathbf{4 1}$ was tested at $100 \mu \mathrm{M}$. After initial 
ADME properties screening using PreADMET (v2.0), molecular docking studies were undertaken using Molegro Virtual Docker 2009 to test the inhibition potency of AChE and GSK-3 $\beta$ among 26 hybrids, and $\mathbf{4 1}$ had significant affinity toward AChE, with a MolDock score of $-183.585 \mathrm{~kJ} / \mathrm{mol}$, and toward GSK-3 $\beta$, with a MolDock score of $-148.821 \mathrm{~kJ} / \mathrm{mol}$. However, enzyme inhibitory activity of compound $\mathbf{4 1}$ against GSK-3 $\beta$ was not reported.

Jiang and co-workers [44] reported a novel series of hybrids, fused with tacrine (4) and compound $42\left(\mathrm{GSK}-3 \beta\right.$ inhibitor, $\left.\mathrm{IC}_{50}=1.1 \mathrm{nM}\right)$ which was reported by the Sivaprakasam group [45]. The most promising hybrid $\mathbf{4 3}$ (Figure 3) showed important human AChE and GSK-3 $\beta$ dual-target inhibitory activity $\left(\mathrm{IC}_{50}=6.5 \mathrm{nM}\right.$ for $\mathrm{AChE}, \mathrm{IC}_{50}=66 \mathrm{nM}$ for GSK-3 $\beta$ ), good performance on $\mathrm{A} \beta$ self-aggregation with a $46 \%$ inhibitory rate at $20 \mu \mathrm{M}$, inhibition of tau protein hyperphosphorylation in mouse neuroblastoma $\mathrm{N} 2 \alpha$-Tau cells, less hepatotoxicity, and significant in vivo cognitive improvement in scopolamine-treated ICR mice.

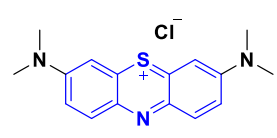

Methylene blue (40)

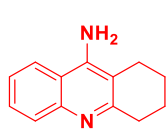

Tacrine (4)

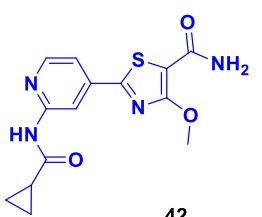

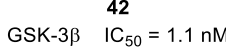
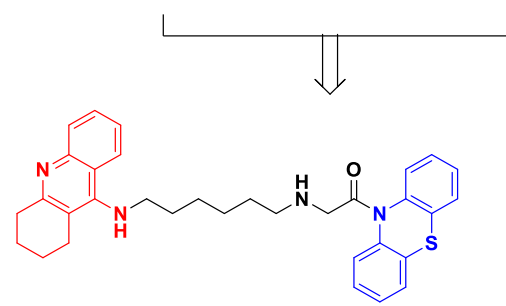

AChE $\stackrel{41}{41} \mathrm{C}_{50}=89 \mathrm{nM}$

GSK-3 3 not reported

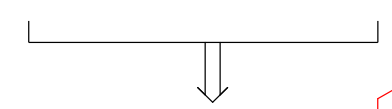

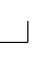

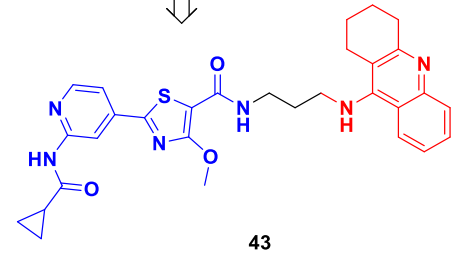

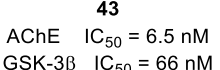

Figure 4. AChE and GSK- $3 \beta$ multi-target strategy

\subsubsection{MAOs}

MAOs are metabolic enzymes that exist in two isoforms, MAO-A and MAO-B, distinguished by their difference on specificity of substrates and inhibitors [46]. MAOs can catalyze the oxidative deamination reactions of various biogenic and xenobiotic amines and play an important role in neurodegenerative diseases, such as $\mathrm{AD}$ and Parkinson disease (PD). The bioactivity of MAO-B is significantly increased in the cerebral cortex and the hippocampus regions of AD 
patients, representing more than $80 \%$ of the total MAOs activity in the brain [47], and the activity and gene expression of MAO-A are also up-regulated in different brain areas [48]. High levels of MAOs catalyze oxidative deamination and increase the production of hydrogen peroxide and reactive oxygen species (ROS) which are responsible for oxidative injuries and the toxic environment characteristics of neurodegeneration [49], and the increased MAO-B levels can enhance astrogliosis in the brain [50]. MAO-A inhibitors are used in the clinic to treat anxiety and depression, which are also common symptoms considered to be risk factors in $\mathrm{AD}$ progression [51], while MAO-B inhibitors are used in the treatment of PD [52]. MAOs inhibitors can increase monoaminergic neurotransmission, decrease ROS formation and oxidative stress, and exert pharmacological effects including antioxidation, neuroprotection and cognitive improvement [53], which are potentially valuable for the treatment of AD. Rasagiline (11) from Teva pharma (Figure 2) is a potent and irreversible selective MAO-B inhibitor approved in 2005 for the treatment of PD and has been in Phase II clinical trials for the treatment of AD.

\subsubsection{AChE and MAOs multi-target strategy}

Ladostigil (44) from Avraham pharma (Figure 5) is currently in Phase II clinical trials for the treatment of mild cognitive impairment (MCI) and Alzheimer's type dementia [54]. This drug shows inhibitory activities against AChE, BChE, MAO-A, and MAO-B in the brain [55], which is combined with the carbamate moiety of the cholinesterases (ChEs) inhibitor rivastigmine (3) and the indolamine moiety of the MAO-B inhibitor rasagiline (11).

In multi-target strategies involving targets $\mathrm{AChE}$ and MAOs for $\mathrm{AD}$ therapies, donepezil (1)-related derivatives and tacrine (4)-related derivatives as MTDLs are still popular. The Unzeta group [56] reported a promising compound, hybrid 46 (Figure 5), which was fused with the benzylpiperidine moiety of donepezil (1) and the indolyl propargylamino moiety of the MAOs inhibitor 45 [57] $\left(\mathrm{IC}_{50}=100 \mathrm{nM}\right.$ for MAO-A, $\mathrm{IC}_{50}=63 \mathrm{nM}$ for MAO-B) (Figure 5), that showed multi-target inhibitory potency against $\mathrm{AChE}, \mathrm{BChE}, \mathrm{MAO}-\mathrm{A}$, and $\mathrm{MAO}-\mathrm{B}\left(\mathrm{IC}_{50}=0.35 \mu \mathrm{M}\right.$ for $\mathrm{AChE}, \mathrm{IC}_{50}=0.46 \mu \mathrm{M}$ for BChE, $\mathrm{IC}_{50}=5.2 \mathrm{nM}$ for MAO-A, $\mathrm{IC}_{50}=43 \mathrm{nM}$ for MAO-B) and presented significant profiles with $47.8 \%$ self-induced $\mathrm{A} \beta$ aggregation inhibition at $10 \mu \mathrm{M}$ and 32.4\% AChE-induced $\mathrm{A} \beta$ aggregation inhibition at $100 \mu \mathrm{M}$. Afterwards, the same group [58] reported that hybrid 48 (Figure 5), with the juxtaposition structure of donepezil (1) and M30 (47) which is potent brain-selective MAOs inhibitor and neuroprotective biometal-chelator [59] $\left(\mathrm{IC}_{50}=\right.$ 
$57 \mathrm{nM}$ for MAO-A, $\mathrm{IC}_{50}=1.5 \mu \mathrm{M}$ for MAO-B) (Figure 5), was a mixed-type ChEs inhibitor and an irreversible MAOs inhibitor with metal-chelating properties $\left(\mathrm{IC}_{50}=1.8 \mu \mathrm{M}\right.$ for $\mathrm{AChE}, \mathrm{IC}_{50}=$ $1.6 \mu \mathrm{M}$ for BChE, $\mathrm{IC}_{50}=6.2 \mu \mathrm{M}$ for MAO-A, $\mathrm{IC}_{50}=10.2 \mu \mathrm{M}$ for MAO-B), and was capable of significantly decreasing scopolamine-induced learning deficits in healthy adult mice. Later, the same group [60] reported another compound, hybrid 49 (Figure 5), which was an improved analogue of $\mathbf{4 8}$ and exhibited excellent ChEs inhibition potency, selective MAO-A inhibition $\left(\mathrm{IC}_{50}\right.$ $=29 \mathrm{nM}$ for $\mathrm{AChE}, \mathrm{IC}_{50}=39 \mathrm{nM}$ for $\mathrm{BChE}, \mathrm{IC}_{50}=10.1 \mu \mathrm{M}$ for MAO-A), strong metal chelating capacity to $\mathrm{Cu}^{2+}$ and $\mathrm{Zn}^{2+}$ ions, and moderate antioxidant properties. Estrada and co-workers [61] reported that hybrid 51 (Figure 5), fused with donepezil (1) and the natural antioxidant cinnamic acid (50) (Figure 5), was ChEs and MAOs dual inhibitors $\left(\mathrm{IC}_{50}=1.75 \mu \mathrm{M}\right.$ for $\mathrm{AChE}, \mathrm{IC}_{50}=0.69$ $\mu \mathrm{M}$ for $\mathrm{BChE}, \mathrm{IC}_{50}=3.5 \mu \mathrm{M}$ for MAO-A, $\mathrm{IC}_{50}=6.0 \mu \mathrm{M}$ for MAO-B) and was able to improve the differentiation of adult subgranular zone (SGZ)-derived neural stem cells into a neuronal phenotype in vitro, thus showing antioxidant, cholinergic, neuroprotective and neurogenic properties. Hybrid 53 (Figure 5) reported by the Sang group [52] was fused with donepezil (1) and the notable MAO-B inhibitor $52\left(\mathrm{IC}_{50}=2.9 \mathrm{nM}\right)$ [62], and showed the potent and balanced inhibitory activities against ChEs and MAOs ( $\mathrm{IC}_{50}=0.56 \mu \mathrm{M}$ for $\mathrm{AChE}, \mathrm{IC}_{50}=2.3 \mu \mathrm{M}$ for $\mathrm{BChE}$, $\mathrm{IC}_{50}=0.3 \mu \mathrm{M}$ for MAO-A, $\mathrm{IC}_{50}=1.4 \mu \mathrm{M}$ for MAO-B). Further investigation confirmed that $\mathbf{5 3}$ could cross the BBB in vitro and abided by Lipinski's rule of five.

The Li group [63] reported that hybrid 55 (Figure 5), fused with the AChEI tacrine (4) and selegiline (54) which is an MAO-B inhibitor approved in 1981 for the treatment of PD, provided a good balance of activities toward ChEs and MAOs $\left(\mathrm{IC}_{50}=22.6 \mathrm{nM}\right.$ for $\mathrm{AChE}, \mathrm{IC}_{50}=9.37 \mathrm{nM}$ for $\mathrm{BChE}, \mathrm{IC}_{50}=0.37 \mu \mathrm{M}$ for MAO-A, $\mathrm{IC}_{50}=0.18 \mu \mathrm{M}$ for MAO-B). The same group [64] reported that hybrid 57 (Figure 5), fused with tacrine (4) and the homoisoflavonoid compound $\mathbf{5 6}$ which is known as an efficient MAO-B selective inhibitor [65] $\left(\mathrm{IC}_{50}=1.06 \mu \mathrm{M}\right.$ for MAO-B) (Figure 5), showed potent inhibitions against ChEs and MAO-B $\left(\mathrm{IC}_{50}=67.9 \mathrm{nM}\right.$ for $\mathrm{AChE}, \mathrm{IC}_{50}=33.0 \mathrm{nM}$ for $\mathrm{BChE}, \mathrm{IC}_{50}=0.401 \mu \mathrm{M}$ for MAO-B). Later, the same group [66] reported another homoisoflavonoid derivative 58 (Figure 5), which showed the desired balance of $\mathrm{AChE}$ and MAO-B inhibitory activities ( $\mathrm{IC}_{50}=3.94 \mu \mathrm{M}$ for $\mathrm{AChE}, \mathrm{IC}_{50}=3.44 \mu \mathrm{M}$ for MAO-B).

Indolotacrine analogue 59 (Figure 5) reported by the Musilek group [67], was a potent inhibitor of ChEs and MAO-A and a weak inhibitor of MAO-B ( $\mathrm{IC}_{50}=1.5 \mu \mathrm{M}$ for $\mathrm{AChE}, \mathrm{IC}_{50}=2.4 \mu \mathrm{M}$ for 


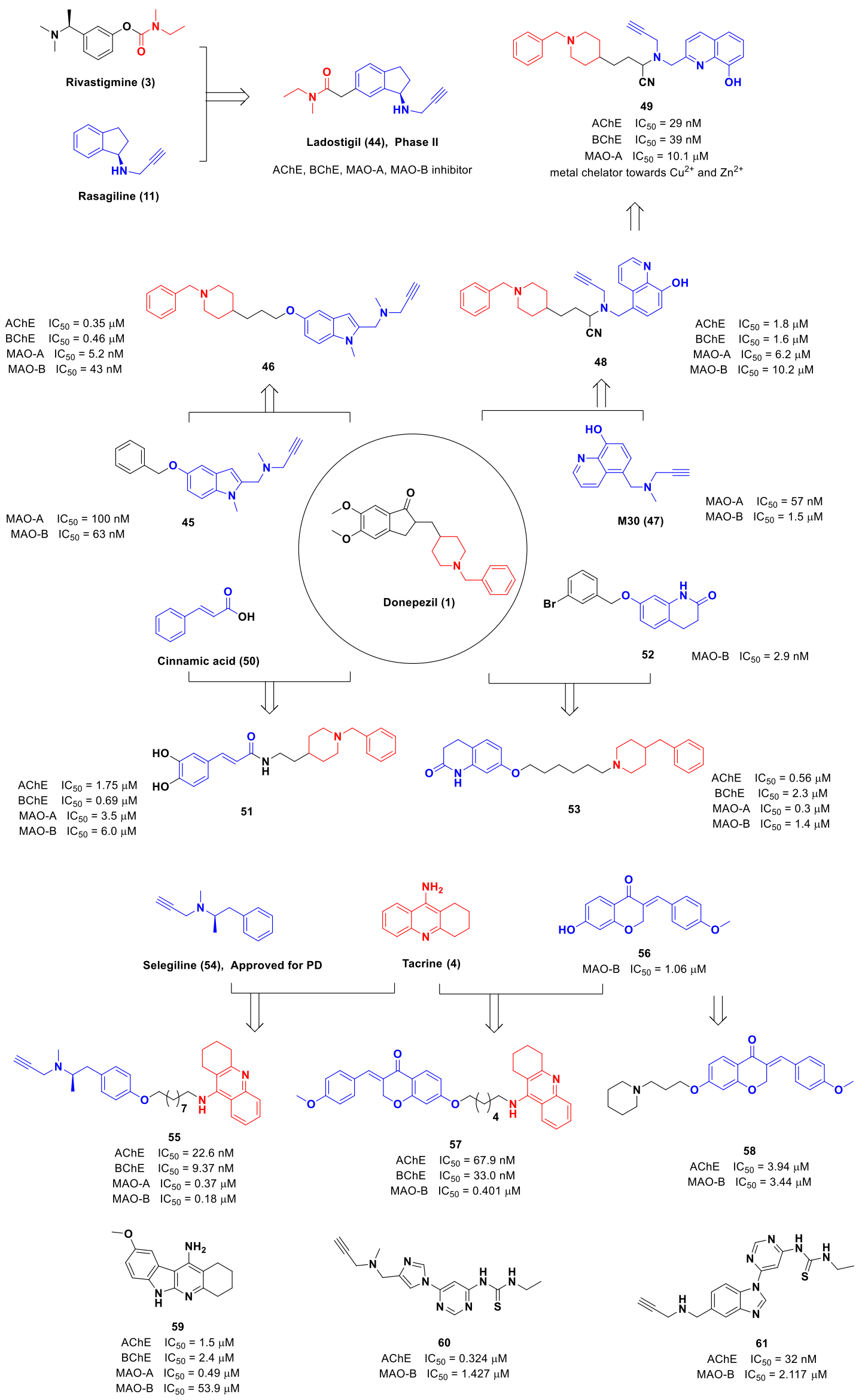

Figure 5. AChE and MAOs multi-target strategy 
$\mathrm{BChE}, \mathrm{IC}_{50}=0.49 \mu \mathrm{M}$ for MAO-A, $\mathrm{IC}_{50}=53.9 \mu \mathrm{M}$ for MAO-B), while its profiles of cytotoxicity in the CHO-K1 cell line $\left(\mathrm{IC}_{50}=5.5 \mu \mathrm{M}\right)$ and hepatotoxicity in the $\mathrm{HepG} 2$ cell line $\left(\mathrm{IC}_{50}=1.22\right.$ $\mu \mathrm{M})$ were not sufficiently good, which was tested by MTT assay, respectively. The Li group [53,

68] reported two series of propargylamine-modified pyrimidinylthiourea derivatives, among which compound $\mathbf{6 0}$ (Figure 5) was the best compound in the first series with good selective inhibitory activity against $\mathrm{AChE}$ and MAO-B $\left(\mathrm{IC}_{50}=0.324 \mu \mathrm{M}\right.$ for $\mathrm{AChE}, \mathrm{IC}_{50}=1.427 \mu \mathrm{M}$ for MAO-B), and demonstrated mild antioxidant ability, good copper chelating ability, and the ability to ameliorate scopolamine-induced cognitive impairment in mice. While compound $\mathbf{6 1}$ (Figure 5) was the most promising compound in the second series with a dual functional profile of targeting $\mathrm{AChE}$ and MAO-B $\left(\mathrm{IC}_{50}=32 \mathrm{nM}\right.$ for $\mathrm{AChE}, \mathrm{IC}_{50}=2.117 \mu \mathrm{M}$ for MAO-B), and showed antioxidant ability, good copper chelating capacity in vitro, and the ability to alleviate scopolamine-induced cognitive impairment in mice.

\subsubsection{Metal ions in the brain}

Bioinorganic chemistry is a significant concept in therapeutic and diagnostic medicine, and the antitumor drug cisplatin ( cis-[ $\left.\left.\mathrm{Pt}\left(\mathrm{NH}_{3}\right)_{2} \mathrm{Cl}_{2}\right]\right)$, a profound prototype in the bioinorganic field, is still a widely used chemotherapeutic agent for cancer and improves the survival rates of patients worldwide [69]. Potential bioinorganic chemical agents are metal ions, active metal complexes, and biometal chelators, which are most often used to limit the adverse effects of metal ions overload, inhibit selected metalloenzymes, or facilitate metal ions redistribution [69]. Excess metal levels in the brain are associated with peptide aggregation and oxidative stress, ultimately leading to cell death, and are responsible for neurodegenerative disorders, such as AD, PD, Creutzfeldt-Jakob disease, and amyotrophic lateral sclerosis [70]. High levels and dysregulation of $\mathrm{Cu}^{2+}, \mathrm{Fe}^{2+}, \mathrm{Zn}^{2+}$, and $\mathrm{Ca}^{2+}$, which are the four most important biometal ions [71], are closely implicated in the pathogenesis of $\mathrm{AD} . \mathrm{Cu}^{2+}$ and $\mathrm{Zn}^{2+}$ have been shown to induce the generation of toxic $\mathrm{A} \beta$ oligomers by binding to $\mathrm{A} \beta$ peptides and influencing the $\mathrm{A} \beta$ aggregation pathway [72], while the redox-active metals, $\mathrm{Cu}(\mathrm{I} / \mathrm{II})$ and $\mathrm{Fe}(\mathrm{II} / \mathrm{III})$, have been demonstrated to generate cytotoxic ROS and cause neuronal damage [73]. Thus, biometal chelators which can down-regulate the high levels of biometals might be a potential therapeutic strategy for the treatment of AD. The approved antifungal drug clioquinol (12) (Figure 2), a moderate metal chelator with 8-hydroxyquinoline as a scaffold, was shown to extract metals from extracellular $\mathrm{A} \beta$ 
aggregates and shift them to copper-carrier proteins in parenchymal cells without perturbing the overall essential metal biochemistry in the brain in recent Phase II clinical trials [74]. PBT-2 (13) from Prana Biotechnology (Figure 2) is a second-generation derivative of clioquinol (12), another metal chelator with an 8-hydroxyquinoline scaffold, and has been in Phase II clinical trials for the treatment of $\mathrm{AD}[75]$

\subsubsection{AChE and metal ions multi-target strategy}

Fernandez-Bachiller and co-workers [76] reported that hybrid $\mathbf{6 2}$ (Figure 6), fused with the AChEI tacrine (4) and the metal chelator drug clioquinol (12), showed potent human AChE inhibitory activity $\left(\mathrm{IC}_{50}=5.5 \mathrm{nM}\right)$ and $\mathrm{Cu}^{2+}$ ion chelating ability based on UV-vis spectrometry. The maximum absorption at $242 \mathrm{~nm}$ of $\mathbf{6 2}$ in Tris buffer suffered a redshift to $248 \mathrm{~nm}$ with the addition of $\mathrm{CuSO}_{4}$, indicating the formation of complex 62-Cu(II). Hybrid 64 (Figure 6) reported by the Kong group [77] is fused with tacrine (4) and a naturally occurring compound flavone (63), and exhibited a significant ability to inhibit $\mathrm{AChE}\left(\mathrm{IC}_{50}=0.13 \mu \mathrm{M}\right)$, along with $\mathrm{Cu}^{2+}$ and $\mathrm{Fe}^{2+}$ ions chelating ability tested by UV-vis spectrometry with wavelength ranging from 200 to $500 \mathrm{~nm}$, $79.1 \%$ self-induced $\mathrm{A} \beta$ aggregation inhibition at $20 \mu \mathrm{M}$, and low toxicity in SH-SY5Y neuroblastoma cells. Xie and co-workers [78] reported that a novel hybrid $\mathbf{6 6}$ (Figure 6), fused with tacrine (4) and coumarin (65) which is a natural product possessing $\mathrm{AChE}$ inhibitory activity [79], displayed the ability to inhibit $\mathrm{AChE}\left(\mathrm{IC}_{50}=92 \mathrm{nM}\right)$, chelate $\mathrm{Cu}^{2+}$ and $\mathrm{Fe}^{2+}$ ions, and inhibit $67.8 \%$ self-induced $\mathrm{A} \beta$ aggregation at $20 \mu \mathrm{M}$. UV-vis spectrometry with wavelength ranging from 200 to $500 \mathrm{~nm}$ was used to test the metal chelating effect of $\mathbf{6 6}$, and the increased absorbance of 66 along with increasing $\mathrm{Cu}^{2+}$ or $\mathrm{Fe}^{2+}$ concentrations indicated the occuring interactions between 66 and these metals.

Compound 67 (Figure 6) with a chromone scaffold reported by the Deng group [80] showed excellent inhibitory potency against rat $\mathrm{AChE}\left(\mathrm{IC}_{50}=70 \mathrm{nM}\right)$, selective biometal chelating ability with $\mathrm{Cu}^{2+}$ via $\mathrm{UV}$-vis spectrometry, moderate antioxidative activity, $59.2 \%$ self-induced $\mathrm{A} \beta$ aggregation inhibition at $25 \mu \mathrm{M}$, and $48.3 \% \mathrm{Cu}^{2+}$-induced $\mathrm{A} \beta$ aggregation inhibition at $25 \mu \mathrm{M}$. The electronic spectra of compound 67 were recorded when the salts $\mathrm{CuCl}_{2}, \mathrm{FeSO}_{4}, \mathrm{ZnCl}_{2}$, or $\mathrm{AlCl}_{3}$ were added, and the curve had a redshift (the peak at $340 \mathrm{~nm}$ shifted to $420 \mathrm{~nm}$ ) with the addition of $\mathrm{CuCl}_{2}$, whereas no significant shift was observed with the other salts, suggesting the formation of complex $67-\mathrm{Cu}(\mathrm{II})$. The $\mathrm{Li}$ group [72] reported a series of non-fused and non-assembly 
pyrimidinylthiourea derivatives by screening hits from 630 compounds. Compound $\mathbf{6 8}$ (Figure 6) was the most promising compound which exhibited potent $\mathrm{AChE}$ inhibition $\left(\mathrm{IC}_{50}=0.204 \mu \mathrm{M}\right)$, specific $\mathrm{Cu}^{2+}$-chelating ability with the maximum absorption dramatically decreased at $290 \mathrm{~nm}$ in the UV-vis spectroscopy assay, antioxidant effects, regulatory function toward $\mathrm{Cu}^{2+}$-induced $\mathrm{A} \beta$ aggregation, low cytotoxicity, and moderate neuroprotection to human neuroblastoma SH-SY5Y

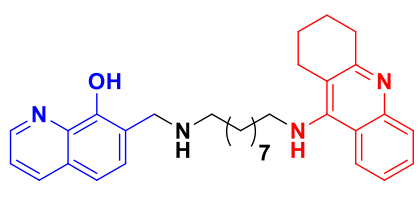

62

AChE $\quad \mathrm{IC}_{50}=5.5 \mathrm{nM}$ metal chelator towards $\mathrm{Cu}^{2+}$

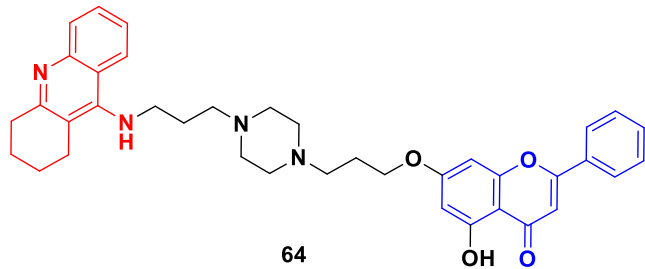

AChE $\quad I_{50}=0.13 \mu \mathrm{M}$ metal chelator towards $\mathrm{Cu}^{2+}$ and $\mathrm{Fe}^{2+}$<smiles>O=c1ccc2ccccc2o1</smiles>

Coumarin (65)

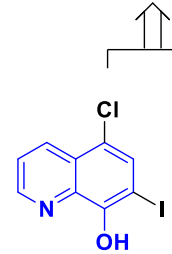

Clioquinol (12)<smiles>Nc1c2c(nc3ccccc13)CCCC2</smiles>

Tacrine (4)

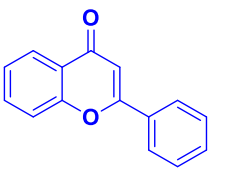

Flavone (63)

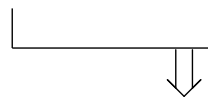<smiles>C=C/C=C(C)\C(NC(=O)CN1CCN(CCOc2ccc3c(C)cc(=O)oc3c2)CC1)=C(/C)CCC</smiles>

66

AChE $\quad \mathrm{IC}_{50}=92 \mathrm{nM}$ metal chelator towards $\mathrm{Cu}^{2+}$ and $\mathrm{Fe}^{2+}$<smiles>CCN(CCCCNC(=O)c1cc(=O)c2c(O)cccc2o1)Cc1ccccc1OC</smiles>

67

AChE $\quad \mathrm{IC}_{50}=70 \mathrm{nM}$ metal chelator towards $\mathrm{Cu}^{2+}$<smiles>CCCN(CCC)Cc1cc(-n2cnc(NC(=S)NCC)c2)ncn1</smiles>

AChE IC IC $_{50}=0.204 \mu \mathrm{M}$ metal chelator towards $\mathrm{Cu}^{2+}$<smiles>COc1cc(/C=C/C(=O)CC(=O)/C=C/c2ccc(O)c(OC)c2)ccc1O</smiles>

Curcumin (69)

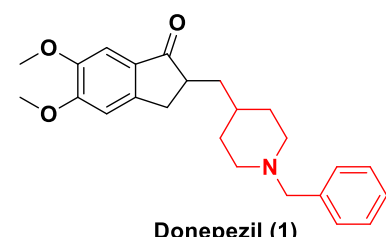

Donepezil (1)

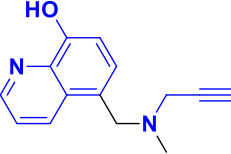

M30 (47)

MAO-A $\quad \mathrm{IC}_{50}=57 \mathrm{nM}$ MAO-B $\quad \mathrm{IC}_{50}=1.5 \mu \mathrm{M}$
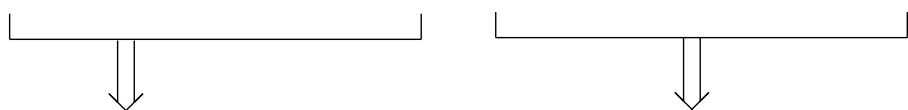

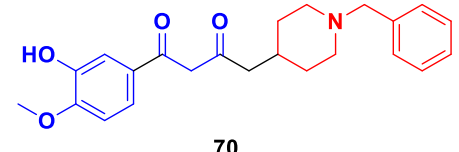

70

AChE $\quad \mathrm{IC}_{50}=0.187 \mu \mathrm{M}$ metal chelator towards $\mathrm{Cu}^{2+}$ and $\mathrm{Fe}^{2+}$

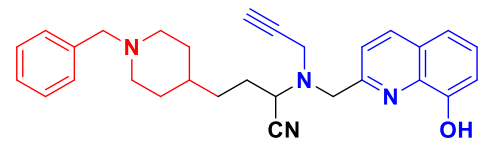

AChE $\quad I C_{50}=29 \mathrm{nM}$

BChE $\quad \mathrm{IC}_{50}=39 \mathrm{nM}$

MAO-A $\quad I_{50}=10.1 \mu \mathrm{M}$

metal chelator towards $\mathrm{Cu}^{2+}$ and $\mathrm{Zn}^{2+}$

Figure 6. AChE and metal ions multi-target strategy 
cells. Further experiments showed appropriate BBB permeability of $\mathbf{6 8}$ both in vitro and in vivo, and memory and cognitive function improvement in scopolamine-induced amnesia mice after the administration of compound $\mathbf{6 8}$. Yan and co-workers [81] reported that a novel compound, hybrid 70 (Figure 6), fused with the AChEI donepezil (1) and curcumin (69) which is extracted from the rhizome of Curcuma longa $L$., showed potent $\mathrm{AChE}$ inhibition $\left(\mathrm{IC}_{50}=0.187 \mu \mathrm{M}\right)$, metal-chelating ability with $\mathrm{Cu}^{2+}$ and $\mathrm{Fe}^{2+}$ via UV-vis spectrometry, $45.3 \% \mathrm{~A} \beta$ self-aggregation inhibition at $20 \mu \mathrm{M}$, and a remarkable antioxidant effect.

\subsubsection{NMDA receptor}

The glutamatergic hypothesis of AD is based on the NMDA receptor which plays a crucial role in modifying major forms of synaptic plasticity, certain types of learning and memory formation, and consolidation of short-term memory into long-term memory under physiological conditions [82], and the states that appropriate inhibition toward NMDA receptor would ameliorate overall condition of $\mathrm{AD}$ patients. The NMDA receptor is a type of ionotropic glutamate receptor composed of two NR1 subunits and two NR2 (NR2A-D) subunits or occasionally NR3 subunit, and can be activated when bound with the excitatory neurotransmitter glutamate or the modulatory agent glycine (Gly). The NMDA receptor exerts important bio-functions in normal synaptic transmission, meaning it cannot be totally antagonized, whereas glutamate-related excitotoxicity and cell death could be caused when NMDA receptors are overstimulated by excess glutamate [83]. An optimal balance of NMDA receptors between glutamate stimulation and glutamate-related excitotoxicity is crucial to achieve the ideal treatment of AD.

Memantine (14) (Table 1) (Figure 2) from Merz Pharma is a noncompetitive antagonist with a relatively low to moderate affinity toward NMDA receptor. Memantine (14) was approved in 2002 and is the only NMDA receptor antagonist drug used in the clinic for the treatment of $\mathrm{AD}$, while it still cannot prevent neuronal loss, stop deterioration of dementia, or reverse the disease progression of AD. Memantine (14) was formulated as tablets with four dose forms $(5,10,15,20$ $\mathrm{mg}$ ) and an oral solution $(10 \mathrm{mg} / \mathrm{mL})$ in the European Union, whereas lower doses of tablet forms $(5,10 \mathrm{mg})$ and a more dilute oral solution $(2 \mathrm{mg} / \mathrm{mL})$ in the USA were licensed a year later. It is well absorbed by oral administration with nearly $100 \%$ bioavailability, it undergoes partial hepatic metabolism with a half-life of $60-100 \mathrm{~h}$, and $48 \%$ of the administered drug is excreted as the original with unchanged structure in the urine [14]. Riluzole (15) (Figure 2) from Covis Pharma is 
a sodium channel blocker approved in 1996 for the treatment of amyotrophic lateral sclerosis (ALS), is currently in Phase II clinical trials for mild AD and has exhibited a cognitive improvement effect. Riluzole (15) can lower extracellular glutamate levels, inhibit presynaptic glutamate release, and enhance glutamate transporter activity [2], suggesting a new clinically applicable therapeutic approach for $\mathrm{AD}$. The withdrawn antihistamine drug dimebon (16) (Figure 2), an NMDA receptor antagonist with the ability to bind AChE and NMDA receptor, was evaluated by Pfizer in Phase III clinical trials for the treatment of moderate to severe AD, but negative results were announced, and the development of dimebon (16) was discontinued [55].

\subsubsection{AChE and NMDA receptor multi-target strategy}

Cholinergic and glutamatergic neuronal systems influence each other through their joint dysfunction, and cholinergic deficits and glutamate-related excitotoxicity are central to AD pathology [84]. Excessive activation of NMDA receptor is implicated in the degenerative process of cholinergic neurons in $\mathrm{AD}$, with the instance that neuronal decline caused by direct injection of NMDA into the rat basal forebrain generates reduced activity of choline acetyltransferase in the cortex [85]. Thus, the AChE and NMDA receptor multi-target strategy can affect the cholinergic and glutamatergic systems and is becoming an important idea because NMDA receptor antagonists can confront neurodegeneration and AChEIs can recover memory and cognition. Namzaric from Allergan approved in 2015 for the treatment of AD is a once-daily fixed-dose combination drug and comprised of memantine (14) hydrochloride and donepezil (1) hydrochloride, under the consideration of reducing pill burden and alleviating administration. In addition, caregivers can sprinkle the drug into food for patients who have difficulty in swallowing.

The Rosini group [86] has done much work to develop novel compounds with dual AChE and NMDA receptor inhibitory potency for potential treatment of AD. Hybrid 72 (Figure 7), named carbacrine, was fused with AChEI tacrine (4) and carbazole (71), and showed dual inhibitory activity against $\mathrm{AChE}$ and NMDA receptor $\left(\mathrm{IC}_{50}=2.15 \mathrm{nM}\right.$ for $\mathrm{AChE}, \mathrm{IC}_{50}=0.74 \mu \mathrm{M}$ for NR1/NR2A), $36.0 \%$ self-induced $\mathrm{A} \beta$ aggregation inhibition, $57.7 \%$ AChE-induced $\mathrm{A} \beta$ aggregation inhibition, and the ability to reduce oxidative stress [87]. Later, compound $\mathbf{7 3}$ (Figure 7), named memagal, was reported as a novel hybrid formed by linking the AChEI galantamine (2) and the NMDA receptor antagonist drug memantine (14) [88]. Memagal (73) showed remarkably inhibitory potency against $\mathrm{AChE}\left(\mathrm{IC}_{50}=1.16 \mathrm{nM}\right)$, and NMDA receptor inhibition which was 
tested by a $\left[{ }^{3} \mathrm{H}\right]$ MK-801 binding assay $\left(\mathrm{K}_{\mathrm{i}}=4.6 \mu \mathrm{M}\right.$, the value was derived from an iterative curve-fitting procedure). Further investigation revealed that hybrid $\mathbf{7 3}$ possessed NR2B-containing NMDA receptor inhibition based on a $\left[{ }^{3} \mathrm{H}\right]$ ifenprodil binding assay $\left(\mathrm{K}_{\mathrm{i}}=4.6 \mu \mathrm{M}\right.$, the value was derived from an iterative curve-fitting procedure) and could inhibit NMDA $(500 \mu \mathrm{M})$ mediated

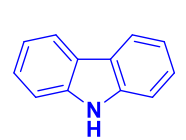

Carbazole (71)
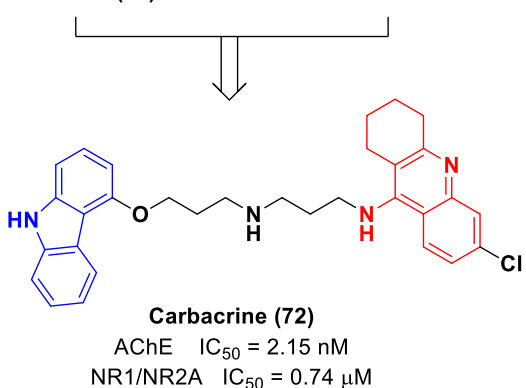

Tacrine (4)<smiles>COc1ccc2c3c1OC(O)CC3CCN2CCO</smiles>

Galantamine (2)

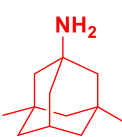

Memantine (14)
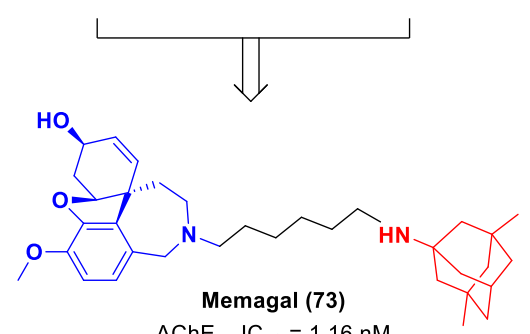

ChE IC ${ }_{50}=1.16 \mathrm{nM}$

NMDA receptor $K_{i}=4.6 \mu \mathrm{M}$ in $\left[{ }^{3} \mathrm{H}\right] \mathrm{MK}-801$ binding assay NMDA receptor $\mathrm{K}_{\mathrm{i}}=4.6 \mu \mathrm{M}$ in $\left[{ }^{3} \mathrm{H}\right]$ ifenprodil binding assay
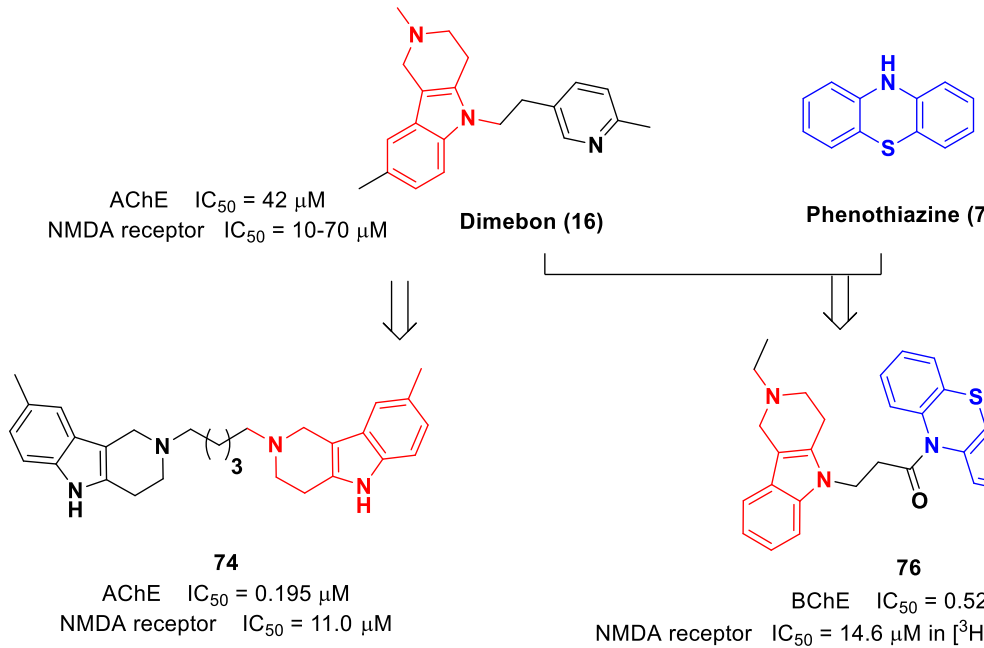

Phenothiazine (75)

Dimebon (16)
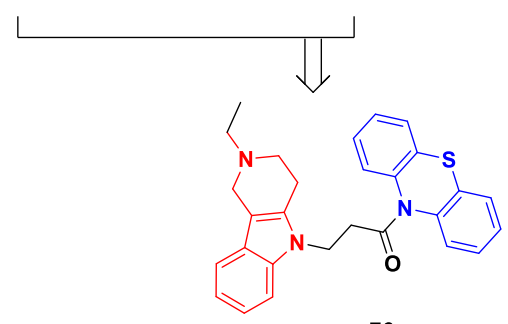

BChE $\quad \mathrm{IC}_{50}=0.52 \mu \mathrm{M}$

NMDA receptor $I_{50}=14.6 \mu \mathrm{M}$ in $\left[{ }^{3} \mathrm{H}\right] \mathrm{MK}-801$ binding assay NMDA receptor $\mathrm{IC}_{50}=13.4 \mu \mathrm{M}$ in $\left[{ }^{3} \mathrm{H}\right]$ ifenprodil binding assay

Figure 7. AChE and NMDA receptor multi-target strategy

neurotoxicity in SH-SY5Y cell viability assay $\left(\mathrm{IC}_{50}=0.28 \mathrm{nM}\right)$, showing a highly potent neuroprotective effect. Dimebon (16) (Figure 7) has a multi-target profile for AD, while the activity against $\mathrm{AChE}$ and NMDA receptor is weak $\left(\mathrm{IC}_{50}=42 \mu \mathrm{M}\right.$ for $\mathrm{AChE}, \mathrm{IC}_{50}=10-70 \mu \mathrm{M}$ for NMDA receptor). In contrast, the optimized dimebon-derivative 74 (Figure 7) showed a potent multi-target profile against both $\mathrm{AChE}$ and NMDA receptor $\left(\mathrm{IC}_{50}=0.195 \mu \mathrm{M}\right.$ for $\mathrm{AChE}, \mathrm{IC}_{50}=$ $11.0 \mu \mathrm{M}$ for NMDA receptor) and $67.0 \%$ self-induced $\mathrm{A} \beta$ aggregation inhibitory potency [89]. Another interesting compound, hybrid 76 (Figure 7), reported by Makhaeva and co-workers [90], 
was fused with dimebon (16) and phenothiazine (75). And compound 76 showed dual $\mathrm{BChE}$ and NMDA receptor inhibition potency with $\mathrm{IC}_{50}=0.52 \mu \mathrm{M}$ for $\mathrm{BChE}, \mathrm{IC}_{50}=14.6 \mu \mathrm{M}$ for NMDA receptor in a $\left[{ }^{3} \mathrm{H}\right] \mathrm{MK}-801$ binding assay, and $\mathrm{IC}_{50}=13.4 \mu \mathrm{M}$ for NMDA receptor in a $\left[{ }^{3} \mathrm{H}\right]$ ifenprodil binding assay.

\subsubsection{5-HT receptors}

The serotonergic neurotransmitter system has crucial physiological functions in emotion and depression, while it is implicated with the cholinergic system in cognitive function of neurodegenerative disease [91]. 5-HT, also named serotonin, is considered as an inhibitory neurotransmitter compared with the excitatory neurotransmitter glutamate, while 5-HT has the bio-function to generate feelings of well-being and happiness, suggesting that the concentration of 5-HT should be increased and the serotonergic system should be enhanced in depressive disorder. Selective serotonin reuptake inhibitors (SSRIs), such as fluoxetine and paroxetine, are primarily approved as antidepressant drugs with the ability to increase 5-HT concentration in the synaptic cleft by inhibiting neuronal reuptake of 5-HT, improving the emotional state of depressive patients. There are seven subtypes of 5-HT receptors (5- $\mathrm{HT}_{1}$ to $5-\mathrm{HT}_{7}$ receptors), which are classified by their structural and functional characteristics. 5- $\mathrm{HT}_{1 \mathrm{~A}}, 5-\mathrm{HT}_{4}, 5-\mathrm{HT}_{6}$, and $5-\mathrm{HT}_{7}$ receptors in the brain are associated with learning and memory. $5-\mathrm{HT}_{1 \mathrm{~A}}$ receptor plays a significant role in therapeutics for major depressive disorder [92], and both agonists and antagonists of this receptor could be potential therapies for $\mathrm{AD}$. $5-\mathrm{HT}_{4}$ receptor is involved in memory processes, and partial agonists of this receptor could be utilized to treat the cognitive symptoms of $\mathrm{AD}$ [93]. 5-HT6 receptor is expressed primarily in the cortex and the hippocampus areas of the brain and is associated with learning and memory processes, and antagonists of this receptor would be beneficial for ameliorating AD symptoms.

Lecozotan (17) (Figure 2) from Pfizer is an orally available, potent and selective 5- $\mathrm{HT}_{1 \mathrm{~A}}$ receptor antagonist in Phase II/III clinical trials for the treatment of AD. PRX-03140 (18) (Figure 2) from Ology Bioservices is a 5- $\mathrm{HT}_{4}$ receptor partial agonist in Phase II clinical trials for the treatment of AD. Idalopirdine (19) (Figure 2) from Otsuka and Lundbeck is an orally available and selective $5-\mathrm{HT}_{6}$ receptor antagonist with promising efficacy and safety data in Phase II trials, but it did not meet its primary efficacy endpoint and was discontinued in Phase III clinical trials [2]. Intepirdine (20) (Figure 2) from Axovant Sciences is another 5- $\mathrm{HT}_{6}$ receptor antagonist in Phase 
III clinical trials for the treatment of mild-to-moderate $\mathrm{AD}$, and Phase II data indicated that the treatment of intepirdine (20) in combination with AChEI donepezil (1) may improve cognitive function in mild-to-moderate $\mathrm{AD}$ patients [2].

\subsubsection{AChE and 5-HT receptors multi-target strategy}

The serotonergic and cholinergic systems have physiological and pathological interactions with each other. Brain functions mediated by $5-\mathrm{HT}_{4}$ receptor require a synergistic effect from cholinergic neurotransmission [94], and activation of 5- $\mathrm{HT}_{4}$ receptor can enhance the release of Ach in the hippocampus [95]. 5- $\mathrm{HT}_{4}$ receptor agonists could promote the nonamyloidogenic cleavage of APP, forming neurotrophic human soluble amyloid precursor protein $\alpha$ (sAPP- $\alpha$ ) fragments and decreasing $\mathrm{A} \beta$ secretion in primary neurons [96]. Meanwhile, 5- $\mathrm{HT}_{6}$ receptor antagonists are thought to have the ability to enhance cholinergic neurotransmission [97]. Thus, $\mathrm{AChE}$ and 5-HT receptors could act synergistically on cognitive deficits, $\mathrm{A} \beta$-mediated damage, and unhealthy emotions, meaning a multi-target strategy targeting these two targets could lead to a potential treatment for $\mathrm{AD}$.

RS67333 (77) (Figure 8) is a 5-HT 4 receptor partial agonist and well-known for its precognitive effect, and showed a synergistic effect with AChEI donepezil (1) on memory performance in mice [98]. RS67333 (77) has the ability to down-regulate $\mathrm{A} \beta$ level by activating 5 - $\mathrm{HT}_{4}$ receptor, directly inhibit human AChE, and the capacity to induce sAPP- $\alpha$ release, reducing amyloid plaque formation [99] $\left(\mathrm{IC}_{50}=403 \mathrm{nM}\right.$ for $\mathrm{AChE}, \mathrm{K}_{\mathrm{i}}=13 \mathrm{nM}$ for $5-\mathrm{HT}_{4}$ receptor, $\mathrm{EC}_{50}=27.2 \mathrm{nM}$ for sAPP- $\alpha$ release). The Dallemagne group [100] reported a further optimized compound 78 (Figure 8), which had a multi-target profile with both $\mathrm{AChE}$ inhibitory effect and 5- $\mathrm{HT}_{4}$ receptor agonist activity $\left(\mathrm{IC}_{50}=95.8 \mathrm{nM}\right.$ for $\mathrm{AChE}, \mathrm{K}_{\mathrm{i}}=4.2 \mathrm{nM}$ for $5-\mathrm{HT}_{4}$ receptor). Interestingly, compound 78 was more antagonistic than agonistic toward $5-\mathrm{HT}_{4}$ receptor, and molecular modeling studies failed to explain the antagonist profile of compound 78. Later, the same group [101] reported that the hybrid 79 (Figure 8), named donecopride, which was fused with RS67333 (77) and donepezil (1), showed dual $\mathrm{AChE}$ inhibition and 5-HT $\mathrm{H}_{4}$ receptor agonist activity $\left(\mathrm{IC}_{50}=16 \mathrm{nM}\right.$ for $\mathrm{AChE}, \mathrm{K}_{\mathrm{i}}$ $=6.6 \mathrm{nM}$ for $5-\mathrm{HT}_{4}$ receptor). Donecopride (79) stimulated the nonamyloidogenic $5-\mathrm{HT}_{4}$ receptor-mediated cleavage of APP and had greater potency in promoting neurotrophic sAPP- $\alpha$ release $\left(\mathrm{EC}_{50}=11.3 \mathrm{nM}\right)$ compared with RS67333 (77) [99]. Donecopride (79), which presented profiles with promising druggability parameters, favorable bioavailability and low toxicity, 
exhibited a precognitive effect with an improvement in memory performance observed at 0.3 and $1 \mathrm{mg} / \mathrm{kg}$ of donecopride (79) administration via intraperitoneal injection in further in vivo studies. Hybrid 81 (Figure 8), reported by the Li group [102], was fused with the AChEI tacrine (4) and vilazodone (80) which is $5-\mathrm{HT}_{1 \mathrm{~A}}$ receptor partial agonist and 5 - $\mathrm{HT}$ reuptake inhibitor for the treatment of major depressive disorder (Figure 8), and exhibited moderate ChEs inhibitory activities, $5-\mathrm{HT}_{1 \mathrm{~A}}$ receptor agonist activity, and 5-HT reuptake inhibitory activity $\left(\mathrm{IC}_{50}=1.72 \mu \mathrm{M}\right.$ for $\mathrm{AChE}, \mathrm{IC}_{50}=0.34 \mu \mathrm{M}$ for $\mathrm{BChE}, \mathrm{EC}_{50}=0.36 \mathrm{nM}$ for $5-\mathrm{HT}_{1 \mathrm{~A}}$ receptor, $\mathrm{IC}_{50}=20.42 \mathrm{nM}$ for 5-HT reuptake). Further investigation showed that compound 81 also possessed good BBB permeability, making it a promising compound for the treatment of depression with cognitive impairment.

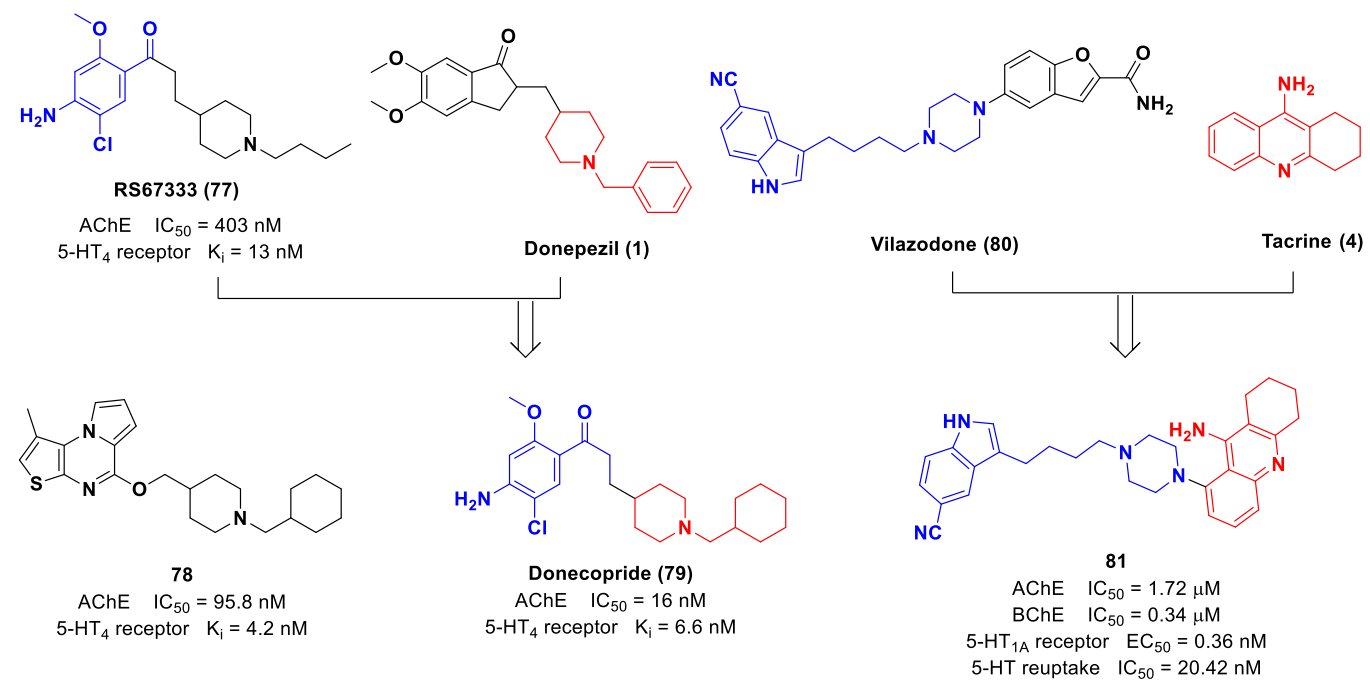

Figure 8. AChE and 5-HT receptors multi-target strategy

\subsubsection{Histamine receptors}

The histaminergic system is composed of histamine and its receptors, plays an important role in maintaining brain homeostasis function and higher brain functions in the CNS, and participates in smooth muscle contraction, dilatation of capillaries, gastric acid secretion, and inflammation in the periphery. Histamine is an endogenous biogenic amine distributed throughout the body that acts as a neurotransmitter in nervous centralis and a local mediator in the periphery, and has high concentrations in the lung, skin, and gastrointestinal tract, carrying out its physiological functions with histamine receptors [103]. Histamine receptors, which are also distributed throughout the 
body, are G protein-coupled receptors with different bio-functions. There are four histamine receptor subtypes, which are $\mathrm{H}_{1}$ receptor, $\mathrm{H}_{2}$ receptor, $\mathrm{H}_{3}$ receptor, and $\mathrm{H}_{4}$ receptor. $\mathrm{H}_{1}$ receptor activation mainly promotes allergic symptoms in the periphery and antagonists against this receptor are typically anti-allergic drugs, such as loratadine, while $\mathrm{H}_{2}$ receptor activation primarily stimulates the secretion of gastric acid and antagonists against this receptor can be antiulcer drugs, such as ranitidine. The interesting $\mathrm{H}_{3}$ receptor is an antoreceptor and heteroreceptor, providing negative feedback on histaminergic system and inhibiting the release of other neurotransmitters when it is activated, and antagonists against this receptor could augment the release of histamine and other neurotransmitters. $\mathrm{H}_{4}$ receptor is the most recently discovered histamine receptor, found in immunocompetent cells, and the development of anti-inflammatory drugs based on $\mathrm{H}_{4}$ receptor is anticipated [103].

ABT-288 (21) (Figure 2) from AbbVie is an $\mathrm{H}_{3}$ receptor antagonist in Phase II clinical trials for the treatment of mild-to-moderate AD, but its clinical efficacy is not sufficient [104]. GSK-239512 (22) (Figure 2) from GlaxoSmithKline is an $\mathrm{H}_{3}$ receptor antagonist in Phase II clinical trials for the treatment of $\mathrm{AD}$ and was discontinued due to lack of improvement in memory test [105], suggesting that single $\mathrm{H}_{3}$ receptor antagonists are not sufficiently effective in treating cognitive dysfunction in AD patients. SUVN-G3031 (structure not disclosed) from Suven Life Sciences is an $\mathrm{H}_{3}$ receptor antagonist in Phase I clinical trials for the treatment of cognitive disorders associated with $\mathrm{AD}$ patients.

\subsubsection{AChE and $\mathrm{H}_{3}$ receptor multi-target strategy}

$\mathrm{H}_{3}$ receptor is considered as a significant target in AD because its activation decreases the presynaptic release of $\mathrm{ACh}$, and its blockade augments the presynaptic release of $\mathrm{ACh}$ and improves cholinergic neurotransmission in the cortex. Thus, a multi-target strategy involving AChE and $\mathrm{H}_{3}$ receptor may exert a synergistic effect on up-regulating synaptic levels of ACh, which is a potential approach for the treatment of $\mathrm{AD}$, but studies exploring this strategy have rarely been reported.

Huang and co-workers [106] reported a series of compounds with a quinoxaline scaffold that showed related inhibitory activities against $\mathrm{AChE}, \mathrm{H}_{3}$ receptor, and $\mathrm{BACE}-1$ targets. The structure of the compounds was first designed to fuse the BACE-1 inhibitor $82\left(\mathrm{IC}_{50}=11 \mathrm{nM}\right)$ with the AChEI compound 83, named BYYT-25 $\left(\mathrm{IC}_{50}=50 \mathrm{nM}\right)$, two compounds reported by the same 
group. In addition, the dihydroquinazoline moiety of $\mathbf{8 2}$ and benzyl pyrrolidine fragment of $\mathbf{8 3}$ were selected to assemble the scaffold of novel $\mathrm{H}_{3}$ receptor inhibitor. Then, a virtual database consisting of plentiful compounds with novel scaffolds was screened on a pharmacophore model of BACE-1 inhibitor and next filtered by a molecular docking model of AChEI, resulting in the selection of 17 quinoxaline derivatives. Among these compounds, hybrid 84 (Figure 9) showed the most promising profiles, with potent activity toward $\mathrm{AChE}, \mathrm{H}_{3}$ receptor, and BACE-1 targets $\left(\mathrm{IC}_{50}\right.$ $=483 \mathrm{nM}$ for $\mathrm{AChE}, \mathrm{IC}_{50}=280 \mathrm{nM}$ for $\mathrm{H}_{3}$ receptor antagonism, $\mathrm{IC}_{50}=189 \mathrm{nM}$ for $\mathrm{H}_{3}$ receptor inverse agonism, 46.64\% inhibition for BACE-1 at $20 \mu \mathrm{M}$ ) and high selectivity for $\mathrm{H}_{3}$ receptor over $\mathrm{H}_{1}, \mathrm{H}_{2}$ or $\mathrm{H}_{4}$ receptors. Further receptor-binding studies of hybrid $\mathbf{8 4}$ demonstrated that it could achieve several key interactions with AChE and BACE-1, suggesting that quinoxaline derivatives may be a potential therapeutic for $\mathrm{AD}$.
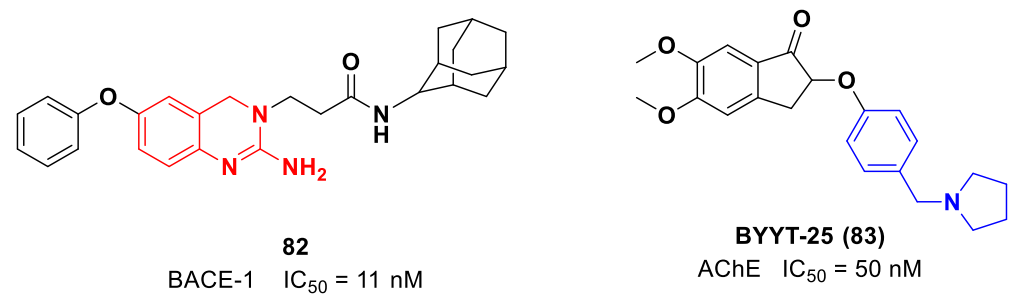

AChE $\quad \mathrm{IC}_{50}=50 \mathrm{nM}$

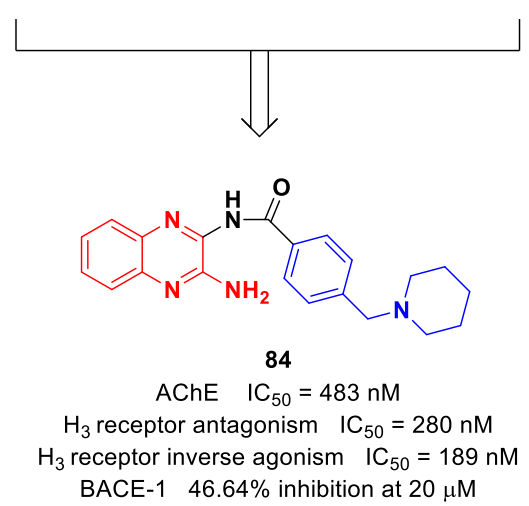

Figure 9. AChE and $\mathrm{H}_{3}$ receptor multi-target strategy

\subsubsection{PDEs}

PDEs are enzymes with the ability to break phosphodiester bonds, and usually referred to cyclic nucleotide phosphodiesterases. They are a group of enzymes that can hydrolyze and degrade intracellular second messengers, such as cyclic adenosine monophosphate (cAMP) and cyclic guanosine monophosphate (cGMP), thus playing a major role in cell signal transduction throughout the brain and the periphery [107]. PDEs are classified into eleven isoenzyme families, 
from PDE1 to PDE11, of which most have several subtypes, contributing to in total 100 specific human PDEs according to the current estimation [108]. Among these families, PDE4, 7, and 8 are specific enzymes for cAMP hydrolysis, and PDE5, 6, and 9 are specific enzymes for cGMP hydrolysis. PDE1, 2, 3, 10, and 11 are dual-substrate enzymes that can hydrolyze both cAMP and cGMP [109]. PDEs with the ability to degrade second messengers are important regulators of signal transduction in neuroplasticity and neuroprotection, and thus, PDEs inhibitors with the capacity to up-regulate the concentrations of cAMP and cGMP are receiving increased attention as potential agents to treat cognitive decline in AD. In addition, the nitric oxide/soluble guanylyl cyclase/cGMP (NO/sGC/cGMP) signaling pathway plays a pivotal role in learning and memory by regulating synaptic transmission and synaptic plasticity in the hippocampus and the cerebral cortex [110], and PDEs inhibitors could have a positive effect on that pathway.

Vinpocetine from Gedeon Richter is a PDE1 inhibitor for the treatment of dementia and cognitive disorders that was approved in 1980, but it was reported to be ineffective on cognitive impairment in AD patients [109]. Cilostazol from Otsuka Pharma is an oral PDE3 inhibitor for the improvement of various symptoms of chronic arterial obstruction and was originally launched in 1988. Cilostazol was tested as a co-treatment with the AChEI donepezil (1) for patients with mild-to-moderate AD. Rolipram from the National Institute of Mental Health is a PDE4D inhibitor in Phase II clinical trials for the treatment of major depression and had beneficial effects in a hippocampal-dependent memory assay, confirming that PDE4D plays a crucial role in memory consolidation [111]. MK-0952 (23) (Figure 2) from Merck is a PDE4 inhibitor in Phase II clinical trials for the treatment of mild-to-moderate AD, but no recent report could be found. PF-04447943 (24) (Figure 2) from Pfizer is a PDE9A inhibitor in Phase I clinical trials for the treatment of sickle cell disease and was tested in Phase II clinical trials for the treatment of mild-to-moderate $\mathrm{AD}$, while it was discontinued in 2011 due to the absence of any effects on cognition. BI-409306 (25) (Figure 2) from Boehringer Ingelheim, a PDE9A inhibitor in Phase II clinical trials for the treatment of schizophrenia, was evaluated in Phase II clinical trials for the treatment of cognitive impairment in $\mathrm{AD}$ patients, and it was discontinued because the efficacy endpoint was not met.

\subsubsection{AChE and PDEs multi-target strategy}

PDEs have eleven isoenzyme families with extensive physiological functions, meaing PDEs could be drug targets in many signaling pathways. Whereas multi-target strategies involving 
targets of AChE and PDEs are rarely reported, indicating that such potential therapies would need to be explored for the treatment of AD. As a special cGMP hydrolytic enzyme, PDE5 has only one hypotype, PDE5A, and is distributed in the hippocampus, cortex and cerebellum of the brain [112]. Tadalafil (85) (Figure 10) of Lilly Icos, a selective PDE5 inhibitor drug launched in 2003 for the treatment of erectile dysfunction (ED), was found that it has the ability to reverse cognitive impairment and improve learning and memory in J20 transgenic mouse model of AD [113].

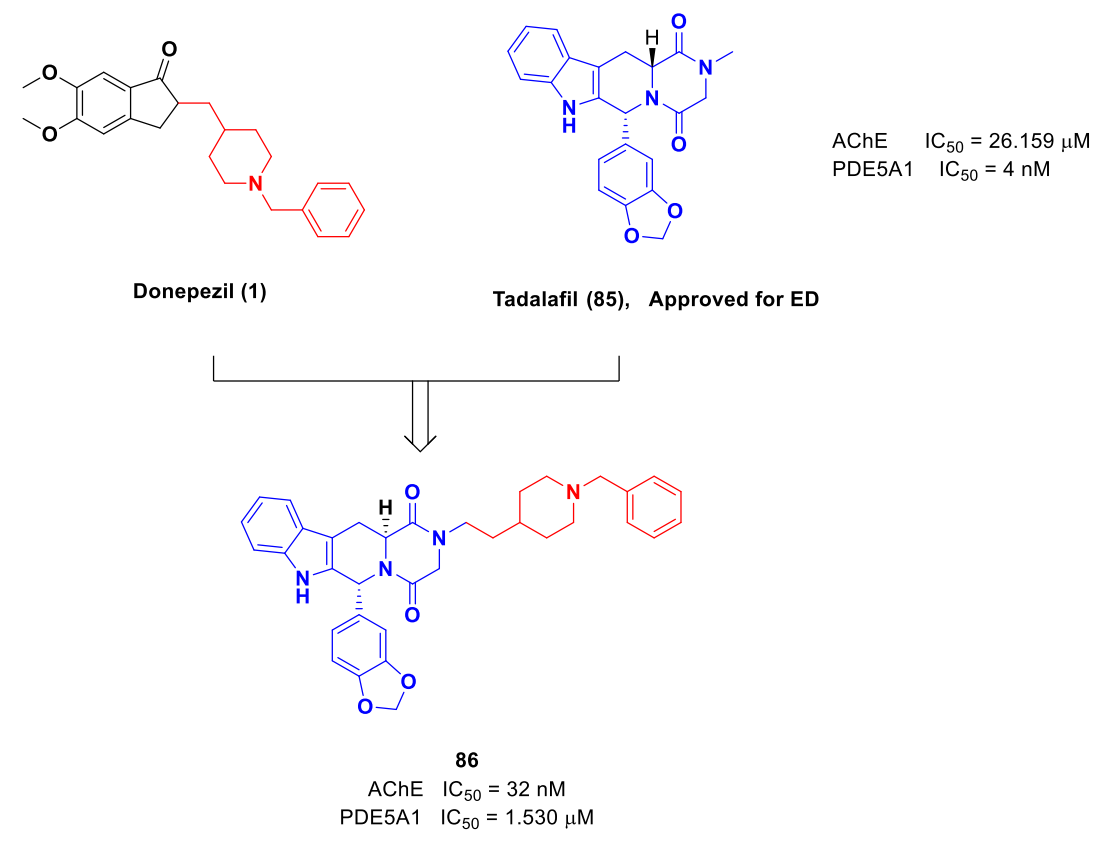

Figure 10. AChE and PDEs multi-target strategy

Repurposing or redeveloping existing drugs for new uses is an important drug discovery strategy with effective and quick characteristics. Through the screening of old drug library, the Li group [114] found that PDE5A inhibitor drug tadalafil (85) has certain AChE inhibitory potency $\left(\mathrm{IC}_{50}=26.159 \mu \mathrm{M}\right.$ for AChE, $\mathrm{IC}_{50}=4 \mathrm{nM}$ for PDE5A1 $)$. The long half-life and safety of tadalafil (85) for the chronic treatments of ED and hypertension make it a good lead compound to discover dual-target inhibitors against AChE and PDE5, being a potential therapy for the treatment of AD. To further explore this synergistic therapeutic route, a series of novel tadalafil (85) derivatives, as the first-generation of dual-target inhibitors toward AChE and PDE5, were synthesized and biologically evaluated. The most promising compound 86 (Figure 10), fused with AChEI donepezil (1) and tadalafil (85), exhibited good inhibitory potency against both targets of AChE and PDE5 $\left(\mathrm{IC}_{50}=32 \mathrm{nM}\right.$ for $\mathrm{AChE}, \mathrm{IC}_{50}=1.530 \mu \mathrm{M}$ for PDE5A1), excellent selectivity among 
relative enzymes $\left(\mathrm{IC}_{50}=3.880 \mu \mathrm{M}\right.$ for $\mathrm{BChE}, \mathrm{IC}_{50}>100 \mu \mathrm{M}$ for PDE2A1, PDE3A, PDE4D3, PDE6C, PDE7A and PDE9A2), and improved BBB penetrability. Further in vivo experiments showed that citrate of $\mathbf{8 6}$ could reverse the cognitive dysfunction in scopolamine-induced AD mice with comparable curative effect against donepezil (1), and had effect on enhancing cAMP response element-binding protein (CREB) phosphorylation, a crucial factor in memory formation and synaptic plasticity [115], by increasing cGMP levels, which may ameliorate the cognitive impairment and restore synaptic function in AD.

\section{Multi-target strategies without AChE}

Multi-target strategies are not limited to strategies involving $\mathrm{AChE}$, and more diverse structures of hits could be designed based on the specific and multiple protein pockets of AD-associated targets. In the disease network of $\mathrm{AD}$, several targets involving $\mathrm{AChE}$ or not, could implicated with others, and their respective signaling pathways could cross with others, contributing together to the development of $\mathrm{AD}$ progression. The importance of $\mathrm{AChE}$ in disease network is prominent, while the potential possibility among other targets should not be neglected for AD therapy. Thus, seeking the specific relationships in the disease network between targets without AChE is also a significant strategy for the treatment of $\mathrm{AD}$. In this section, three multi-target strategies without $\mathrm{AChE}$ are demonstrated (Figure 1).

\subsection{BACE-1 and GSK-3 $\beta$ multi-target strategy}

The histopathological hallmarks in the brain of AD patients are senile plaques and NFTs, and BACE-1 and GSK-3 $\beta$ are two key targets responsible for each pathological cascade, suggesting that a dual inhibitor against BACE-1 and GSK-3 $\beta$ could produce a downstream synergistic effect [116]. The Cavalli group [117] reported a series of triazinone derivatives as the first generation of dual BACE-1 and GSK-3 $\beta$ inhibitors, which were derived from a cyclic amide group and a guanidine moiety under the guidance of a fragment-based approach. Among these derivatives possessing balanced micromolar affinities for both BACE-1 and GSK-3 $\beta$, compound 87 (Figure 11) showed the most promising profiles, with the best balanced inhibitory potency against BACE-1 and GSK-3 $\beta\left(\mathrm{IC}_{50}=18.03 \mu \mathrm{M}\right.$ for BACE-1, $\mathrm{IC}_{50}=14.67 \mu \mathrm{M}$ for GSK-3 $\beta$ ), effective neuroprotective and neurogenic activities due to the modulation of GSK-3 $\beta$ and simultaneous inhibition toward both targets, and no sign of neurotoxicity in glial and neuronal cells. Further in 
vivo investigation in mice indicated that compound $\mathbf{8 7}$ displayed good drug-like properties in oral bioavailability (66\%) and BBB penetration (a brain concentration of $0.62 \mu \mathrm{M}$ of compound 87 was observed $30 \mathrm{~min}$ later when a very low dose of $3 \mathrm{mg} / \mathrm{kg}$ was administered with compound 87). The Belluti group [118] reported another series of dual inhibitors targeting BACE-1 and GSK-3 $\beta$ that showed good neuroprotective and pharmacokinetic properties. This series of inhibitors was based on the natural product curcumin (69) which possesses efficacy and safety for both prevention and treatment of various disorders [119]. In this study, the curcumin derivative compound $\mathbf{8 8}$ (Figure 11) had the most balanced concurrent inhibitory activity against BACE-1 and GSK-3 $\beta\left(\mathrm{IC}_{50}=0.97 \mu \mathrm{M}\right.$ for BACE-1, $\mathrm{IC}_{50}=0.90 \mu \mathrm{M}$ for GSK-3 $\left.\beta\right)$, exerted neuroprotective activity by inducing the $\mathrm{NAD}(\mathrm{P}) \mathrm{H}$ :quinone oxidoreductase 1 (NQO1) enzyme, possessed a weak antioxidant effect, and showed brain permeability, making it a promising drug candidate.

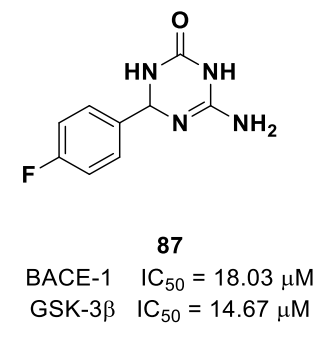

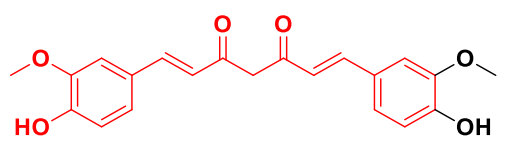

Curcumin (69)

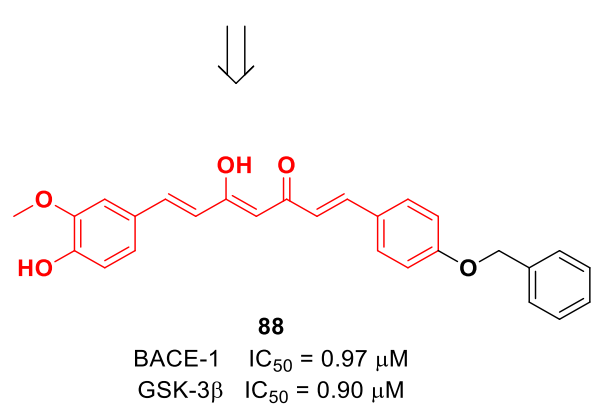

Figure 11. BACE-1 and GSK-3 $\beta$ multi-target strategy

\subsection{MAO-B and metal ions multi-target strategy}

The Li group [120] reported that a series of novel hybrids fused with the main pharmacophores of selegiline (54), an MAO-B inhibitor $\left(\mathrm{IC}_{50}=18.5 \mathrm{nM}\right)$ approved in 1981 for the treatment of PD, and clioquinol (12), a moderate metal chelator approved as an antifungal drug, showed MAO-B inhibitory potency, antioxidant activity, biometal chelating ability, and effective inhibition against $\mathrm{Cu}(\mathrm{II})$-induced $\mathrm{A} \beta$ aggregation. The most promising compound 89 (Figure 12) exhibited good inhibitory activity against MAO-B ( $\mathrm{IC}_{50}=0.21 \mu \mathrm{M}$ for MAO-B), good antioxidant activity (oxygen radical absorbance capacity $(\mathrm{ORAC})=4.2$ ), and the ability to permeate the BBB in a PAMPA-BBB study. UV-vis spectrometry was used to investigate the metal-chelating ability of 
compound 89, and the results indicated that it could interact with $\mathrm{Cu}^{2+}, \mathrm{Fe}^{2+}$, and $\mathrm{Zn}^{2+}$ metal ions, especially with $\mathrm{Cu}^{2+}$ ion. The maximum absorption peak at $236 \mathrm{~nm}$ of the solution of compound $\mathbf{8 9}$ was obviously decreased and another absorption peak at $276 \mathrm{~nm}$ suffered a redshift to $282 \mathrm{~nm}$ after $\mathrm{CuSO}_{4}$ was added to the solution, while the specific absorption peaks at $236 \mathrm{~nm}$ and $276 \mathrm{~nm}$ shifted slightly after $\mathrm{FeSO}_{4}$ or $\mathrm{ZnCl}_{2}$ was added to the solution, respectively, suggesting that compound $\mathbf{8 9}$ possess the biometal chelating ability. These results indicated that compound $\mathbf{8 9}$ had the potential profiles to be a good multi-target and multifunctional agent for the treatment of AD.

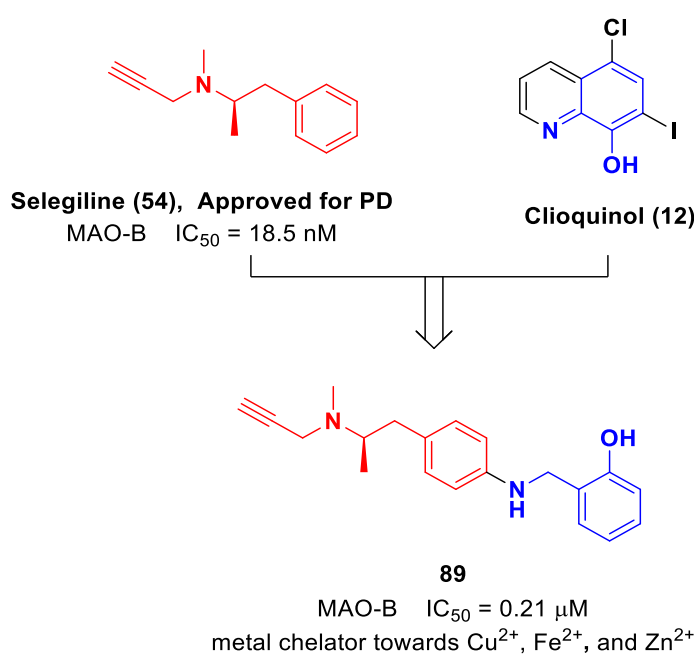

Figure 12. MAO-B and metal ions multi-target strategy

\subsection{PDEs and metal ions multi-target strategy}

Down-regulation of the NO/sGC/cGMP pathway and impaired homeostasis of biometals play significant and malignant roles in $\mathrm{AD}$, suggesting that PDEs inhibition and metal chelation would have synergistic therapeutic effect and a multi-target strategy involving PDEs and metal chelating is possible.

Su and co-workers [121] reported that a novel hybrid 90 (Figure 13), fused with the PDE9A inhibitor PF-04447943 (24) (Figure 2) and clioquinol (12) which is a moderate metal chelator approved as an antifungal drug, showed inhibitory potency against PDE9 $\left(\mathrm{IC}_{50}=34 \mathrm{nM}\right)$ with high selectivity over other PDEs (55-fold), notable $\mathrm{Cu}^{2+}$-induced $\mathrm{A} \beta$ aggregation inhibition, and favorable BBB permeability. Hybrid $\mathbf{9 0}$ also had remarkable metal-chelating capacity toward metal ions $\mathrm{Cu}^{2+}, \mathrm{Fe}^{2+}$, and $\mathrm{Zn}^{2+}$, tested by $\mathrm{UV}$-vis spectrophotometry. The absorption peaks at 259 $\mathrm{nm}$ of the solution of compound $\mathbf{9 0}$ suffered a redshift to $273 \mathrm{~nm}$ after incubation of compound $\mathbf{9 0}$ with $\mathrm{Cu}^{2+}$, and similar results were obtained upon incubation of compound 90 with $\mathrm{Fe}^{2+}$ and $\mathrm{Zn}^{2+}$. 
These results indicated that hybrid 90 could be a promising compound for the treatment of AD. A novel series of hybrids, reported by the Li group [122], were fused with the pharmacophores of the moderate metal chelator clioquinol (12) and the PDE4D inhibitor moracin $\mathrm{M}(\mathbf{9 1})\left(\mathrm{IC}_{50}=2.91 \mu \mathrm{M}\right)$ which is a natural product isolated from the root bark of Morus alba Linn with antioxidant and anti-inflammatory activities. The most promising compound, hybrid 92 (Figure 13), had good profiles with excellent PDE4D inhibitory potency $\left(\mathrm{IC}_{50}=0.32 \mu \mathrm{M}\right)$, significant antioxidant effects, appropriate biometal chelating functions toward the metal ions $\mathrm{Cu}^{2+}, \mathrm{Fe}^{2+}$, and $\mathrm{Zn}^{2+}$ according to a $\mathrm{UV}$-vis spectroscopy assay, and the ability to modulate self-induced $\mathrm{A} \beta$ aggregation and $\mathrm{Cu}^{2+}$-induced $\mathrm{A} \beta$ aggregation.

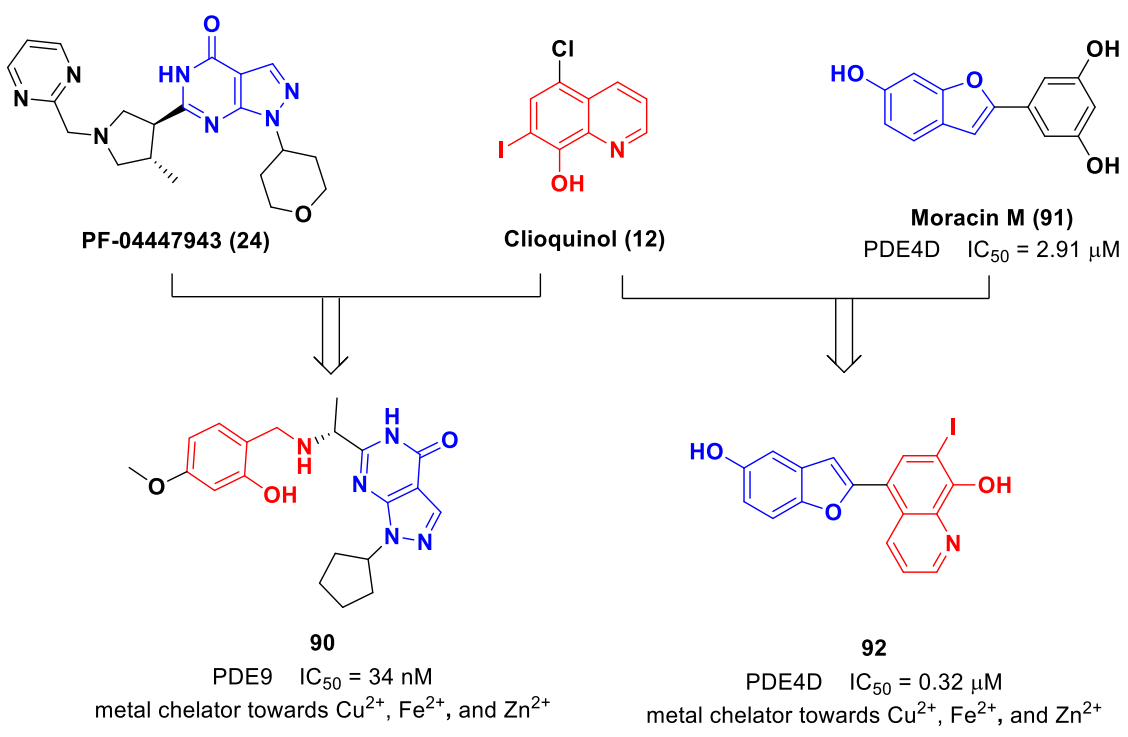

Figure 13. PDEs and metal ions multi-target strategy

\section{Conclusion}

Currently, AD is an incurable disease with a complicated disease network and brings enormous suffering to patients and their families. Therefore, there is an urgent need to be met for the society. Huge efforts have been made by research groups worldwide to conquer this disease, and lots of AD-related targets have been found with the attempt to solve the puzzle caused by the disease network. Nine major targets were discussed in this overview, among which AChE demonstrates a significant influence on this field, and corresponding single-target drugs or candidates (25 instances) were exhibited. Moreover, the therapies based on other targets, such as cyclooxygenase 
(COX) and 5-lipoxygenase (5-LOX) [123] which are not discussed here, can also be considered as potential targets for the possible treatment of AD. There are also some NCEs, with multifunction effects and overall cognitive improvement on AD-related animal models, not discussed here in detail because their corresponding binding-targets have not been clearly figured out. But these NCEs have showed enough and excellent curative effect to be drug candidates for the treatment of AD. For example, mecripyrine (SCR1693) of Yene Pharma, an AChE inhibitor which was developed based on multi-target design strategy, could remarkably attenuate tau hyperphosphorylation and improve memory deficits, and preserve dendrite morphologies as well as spine density [124]. It is in the Phase I clinical trials in China for the potential treatment of AD [125].

Considering the intricate pathogenesis of $\mathrm{AD}$ and the shortcomings of single-target drugs, we think the multi-target design strategies are the frontier scientific research for potential treatment of $\mathrm{AD}$ because efficient and synergetic modulation toward several targets could be realized by multi-target inhibitors to better affect the disease network and control AD progression than single-target drugs. Eleven multi-target design strategies were discussed in this overview and various promising compounds (42 instances) for the potential treatment of AD were presented. It is deficient for current situation that existing scaffolds are still not sufficient to enrich the compound libraries for $\mathrm{AD}$ treatment, and most designed compounds with dual-target activities are hybrids of known structures or drugs. Nevertheless, natural products [126] and computer-aided drug design could be beneficial and promising to explore novel scaffolds and structures with a better curative effect. More efforts are needed to make the multi-target compounds eventually developed into new drugs which could be successfully used in the clinic as ideal AD treatments.

\section{Acknowledgements}

The authors thank the National Natural Science Foundation of China (No. 81874289) for financial support. This study was financed in part by the "Double First-Class" University project CPU2018GY04, China Pharmaceutical University.

\section{References}

[1] K. Blennow, M.J. de Leon, H. Zetterberg, Alzheimer's disease, Lancet 368 (2006) 387-403. 
[2] S.Y. Hung, W.M. Fu, Drug candidates in clinical trials for Alzheimer's disease, J. Biomed. Sci. 24 (2017) 47.

[3] A. Alzheimer, Uber eine eigenartige Erkrankung der Hirnrinde, Allg. Z. Psychiatr. 64 (1907) 146-148.

[4] M.G. Ulep, S.K. Saraon, S. McLea, Alzheimer disease, J. Nurse. Pract. 14 (2018) 129-135.

[5] C.A. Lane, J. Hardy, J.M. Schott, Alzheimer's disease, Eur. J. Neurol. 25 (2018) 59-70.

[6] P. Davies, A.J. Maloney, Selective loss of central cholinergic neurons in Alzheimer's disease, Lancet 308 (1976) 1403-1403.

[7] A.V. Terry, J.J. Buccafusco, The cholinergic hypothesis of age and Alzheimer's disease-related cognitive deficits: Recent challenges and their implications for novel drug development, J. Pharmacol. Exp. Ther. 306 (2003) $821-827$

[8] K.B. Augustinsson, D. Nachmansohn, Distinction between acetylcholine-esterase and other choline ester-splitting enzymes, Science 110 (1949) 98-99.

[9] T.H. Ferreira-Vieira, I.M. Guimaraes, F.R. Silva, F.M. Ribeiro, Alzheimer's disease: targeting the cholinergic system, Curr. Neuropharmacol. 14 (2016) 101-115.

[10] N.H. Greig, T. Utsuki, Q.S. Yu, X.X. Zhu, H.W. Holloway, T. Perry, B. Lee, D.K. Ingram, D.K. Lahiri, A new therapeutic target in Alzheimer's disease treatment: attention to butyrylcholinesterase, Curr. Med. Res. Opin. 17 (2001) 159-165.

[11] E. Giacobini, Selective inhibitors of butyrylcholinesterase: a valid alternative for therapy of Alzheimer's disease?, Drugs Aging 18 (2001) 891-898.

[12] S. Kumar, Dual inhibition of acetylcholinesterase and butyrylcholinesterase enzymes by allicin, Indian J. Pharmacol. 47 (2015) 444-446.

[13] A. Kumar, A. Singh, Ekavali, A review on Alzheimer's disease pathophysiology and its management: an update, Pharmacol. Rep. 67 (2015) 195-203.

[14] F. Zemek, L. Drtinova, E. Nepovimova, V. Sepsova, J. Korabecny, J. Klimes, K. Kuca, Outcomes of Alzheimer's disease therapy with acetylcholinesterase inhibitors and memantine, Expert. Opin. Drug Saf. 13 (2014) 759-774.

[15] L. Ismaili, B. Refouvelet, M. Benchekroun, S. Brogi, M. Brindisi, S. Gemma, G. Campiani, S. Filipic, D. Agbaba, G. Esteban, M. Unzeta, K. Nikolic, S. Butini, J. Marco-Contelles, Multitarget compounds bearing tacrineand donepezil-like structural and functional motifs for the potential treatment of Alzheimer's disease, Prog. Neurobiol. 151 (2017) 4-34.

[16] J.A. Hardy, G.A. Higgins, Alzheimer's disease: the amyloid cascade hypothesis, Science. 256 (1992) 184-185. 
[17] J. Hardy, D.J. Selkoe, The amyloid hypothesis of Alzheimer's disease: progress and problems on the road to therapeutics, Science 297 (2002) 353-356.

[18] D.J. Selkoe, J. Hardy, The amyloid hypothesis of Alzheimer's disease at 25 years, EMBO. Mol. Med. 8 (2016) 595-608.

[19] W.V. Graham, A. Bonito-Oliva, T.P. Sakmar, Update on Alzheimer's disease therapy and prevention strategies, Annu. Rev. Med. 68 (2017) 413-430.

[20] J. Kim, L. Onstead, S. Randle, R. Price, L. Smithson, C. Zwizinski, D.W. Dickson, T. Golde, E. McGowan, Aß40 inhibits amyloid deposition in vivo, J. Neurosci. 27 (2007) 627-633.

[21] P. Scheltens, K. Blennow, M.M.B. Breteler, B. de Strooper, G.B. Frisoni, S. Salloway, W.M. Van der Flier, Alzheimer's disease, Lancet 388 (2016) 505-517.

[22] Y. Luo, B. Bolon, S. Kahn, B.D. Bennett, S. Babu-Khan, P. Denis, W. Fan, H. Kha, J.H. Zhang, Y.H. Gong, L. Martin, J.C. Louis, Q. Yan, W.G. Richards, M. Citron, R. Vassar, Mice deficient in BACE1, the Alzheimer's $\beta$-secretase, have normal phenotype and abolished $\beta$-amyloid generation, Nat. Neurosci. 4 (2001) 231-232.

[23] M.E. Kennedy, A.W. Stamford, X. Chen, K. Cox, J.N. Cumming, M.F. Dockendorf, M. Egan, L. Ereshefsky, R.A. Hodgson, L.A. Hyde, S. Jhee, H.J. Kleijn, R. Kuvelkar, W. Li, B.A. Mattson, H. Mei, J. Palcza, J.D. Scott, M. Tanen, M.D. Troyer, J.L. Tseng, J.A. Stone, E.M. Parker, M.S. Forman, The BACE1 inhibitor verubecestat (MK-8931) reduces CNS $\beta$-amyloid in animal models and in Alzheimer's disease patients, Sci. Transl. Med. 8 (2016) 363ra150.

[24] N. Hawkes, Merck ends trial of potential Alzheimer's drug verubecestat, BMJ. 356 (2017) j845.

[25] A. Satlin, T. Fukushima, Composition comprising an anti-A $\beta$ protofibril antibody and A $\beta$-secretase BACE1 inhibitor for the treatment of alzheimer's disease, WO 2018/081460 A1. (2018)

[26] Y.P. Zhu, K. Xiao, L.P. Ma, B. Xiong, Y. Fu, H.P. Yu, W. Wang, X. Wang, D.Y. Hu, H.L. Peng, J.Y. Li, Q. Gong, Q. Chai, X.C. Tang, H.Y. Zhang, J. Li, J.K. Shen, Design, synthesis and biological evaluation of novel dual inhibitors of acetylcholinesterase and $\beta$-secretase, Bioorg. Med. Chem. 17 (2009) 1600-1613.

[27] S.J. Stachel, C.A. Coburn, T.G. Steele, K.G. Jones, E.F. Loutzenhiser, A.R. Gregro, H.A. Rajapakse, M.T. Lai, M.C. Crouthamel, M. Xu, K. Tugusheva, J.E. Lineberger, B.L. Pietrak, A.S. Espeseth, X.P. Shi, E. Chen-Dodson, M.K. Holloway, S. Munshi, A.J. Simon, L. Kuo, J.P. Vacca, Structure-based design of potent and selective cell-permeable inhibitors of human $\beta$-secretase (BACE-1), J. Med. Chem. 47 (2004) 6447-6450.

[28] T. Mohamed, J.C.K. Yeung, M.S. Vasefi, M.A. Beazely, P.P.N. Rao, Development and evaluation of multifunctional agents for potential treatment of Alzheimer's disease: Application to a pyrimidine-2,4-diamine 
template, Bioorg. Med. Chem. Lett. 22 (2012) 4707-4712.

[29] T. Mohamed, X.B. Zhao, L.K. Habib, J.R. Yang, P.P.N. Rao, Design, synthesis and structure-activity relationship (SAR) studies of 2,4-disubstituted pyrimidine derivatives: dual activity as cholinesterase and A $\beta$-aggregation inhibitors, Bioorg. Med. Chem. 19 (2011) 2269-2281.

[30] M.I. Fernandez-Bachiller, C. Perez, L. Monjas, J. Rademann, M.I. Rodriguez-Franco, New tacrine-4-Oxo-4H-chromene hybrids as multifunctional agents for the treatment of Alzheimer's disease, with cholinergic, antioxidant, and $\beta$-amyloid-reducing properties, J. Med. Chem. 55 (2012) 1303-1317.

[31] E. Viayna, I. Sola, M. Bartolini, A. De Simone, C. Tapia-Rojas, F.G. Serrano, R. Sabate, J. Juarez-Jimenez, B. Perez, F.J. Luque, V. Andrisano, M.V. Clos, N.C. Inestrosa, D. Munoz-Torrero, Synthesis and multitarget biological profiling of a novel family of rhein derivatives as disease-modifying anti-Alzheimer agents, J. Med. Chem. 57 (2014) 2549-2567.

[32] P. Camps, R. El Achab, J. Morral, D. Munoz-Torrero, A. Badia, J.E. Banos, N.M. Vivas, X. Barril, M. Orozco, F.J. Luque, New tacrine-huperzine A hybrids (huprines): highly potent tight-binding acetylcholinesterase inhibitors of interest for the treatment of Alzheimer's disease, J. Med. Chem. 43 (2000) 4657-4666.

[33] F.J. Perez-Areales, N. Betari, A. Viayna, C. Pont, A. Espargaro, M. Bartolini, A. De Simone, J.F.R. Alvarenga, B. Perez, R. Sabate, R.M. Lamuela-Raventos, V. Andrisano, F.J. Luque, D. Munoz-Torrero, Design, synthesis and multitarget biological profiling of second-generation anti-Alzheimer rhein-huprine hybrids, Future Med. Chem. 9 (2017) 965-981.

[34] X.M. Zha, D. Lamba, L.L. Zhang, Y.H. Lou, C.X. Xu, D. Kang, L. Chen, Y.G. Xu, L.Y. Zhang, A. De Simone, S. Samez, A. Pesaresi, J. Stojan, M.G. Lopez, J. Egea, V. Andrisano, M. Bartolini, Novel tacrine-benzofuran hybrids as potent multitarget-directed ligands for the treatment of Alzheimer's disease: design, synthesis, biological evaluation, and X-ray crystallography, J. Med. Chem. 59 (2016) 114-131.

[35] J.L. Dominguez, F. Fernandez-Nieto, M. Castro, M. Catto, M.R. Paleo, S. Porto, F.J. Sardina, J.M. Brea, A. Carotti, M.C. Villaverde, F. Sussman, Computer-aided structure-based design of multitarget leads for Alzheimer's disease, J. Chem. Inf. Model. 55 (2015) 135-148.

[36] F. Belluti, A. De Simone, A. Tarozzi, M. Bartolini, A. Djemil, A. Bisi, S. Gobbi, S. Montanari, A. Cavalli, V. Andrisano, G. Bottegoni, A. Rampa, Fluorinated benzophenone derivatives: Balanced multipotent agents for Alzheimer's disease, Eur. J. Med. Chem. 78 (2014) 157-166.

[37] M.T. Gabr, M.S. Abdel-Raziq, Design and synthesis of donepezil analogues as dual AChE and BACE-1 inhibitors, Bioorg. Chem. 80 (2018) 245-252. 
[38] F. Panza, V. Solfrizzi, D. Seripa, B.P. Imbimbo, M. Lozupone, A. Santamato, C. Zecca, M.R. Barulli, A. Bellomo, A. Pilotto, A. Daniele, A. Greco, G. Logroscino, Tau-centric targets and drugs in clinical development for the treatment of Alzheimer's disease, Biomed. Res. Int. (2016) 3245935.

[39] J. Avila, F. Wandosell, F. Hernandez, Role of glycogen synthase kinase-3 in Alzheimer's disease pathogenesis and glycogen synthase kinase-3 inhibitors, Expert. Rev. Neurother. 10 (2010) 703-710.

[40] M. Iba, J.L. Guo, J.D. McBride, B. Zhang, J.Q. Trojanowski, V.M.Y. Lee, Synthetic tau fibrils mediate transmission of neurofibrillary tangles in a transgenic mouse model of Alzheimer's-like tauopathy, J. Neurosci. 33 (2013) 1024-1037.

[41] C.J. Phiel, C.A. Wilson, V.M.Y. Lee, P.S. Klein, GSK-3 $\alpha$ regulates production of Alzheimer's disease amyloid- $\beta$ peptides, Nature 423 (2003) 435-439.

[42] T. del Ser, K.C. Steinwachs, H.J. Gertz, M.V. Andres, B. Gomez-Carrillo, M. Medina, J.A. Vericat, P. Redondo, D. Fleet, T. Leon, Treatment of Alzheimer's disease with the GSK-3 inhibitor tideglusib: a pilot study, J. Alzheimers Dis. 33 (2013) 205-215.

[43] A.L. Hui, Y. Chen, S.J. Zhu, C.S. Gan, J. Pan, A. Zhou, Design and synthesis of tacrine-phenothiazine hybrids as multitarget drugs for Alzheimer's disease, Med. Chem. Res. 23 (2014) 3546-3557.

[44] X.Y. Jiang, T.K. Chen, J.T. Zhou, S.Y. He, H.Y. Yang, Y. Chen, W. Qu, F. Feng, H.P. Sun, Dual GSK-3ß/AChE inhibitors as a new strategy for multitargeting anti-Alzheimer's disease drug discovery, ACS. Med. Chem. Lett. 9 (2018) 171-176.

[45] P. Sivaprakasam, X. Han, R.L. Civiello, S. Jacutin-Porte, K. Kish, M. Pokross, H.A. Lewis, N. Ahmed, N. Szapiel, J.A. Newitt, E.T. Baldwin, H. Xiao, C.M. Krause, H. Park, M. Nophsker, J.S. Lippy, C.R. Burton, D.R. Langley, J.E. Macor, G.M. Dubowchik, Discovery of new acylaminopyridines as GSK-3 inhibitors by a structure guided in-depth exploration of chemical space around a pyrrolopyridinone core, Bioorg. Med. Chem. Lett. 25 (2015) 1856-1863.

[46] J.P. Johnston, Some observations upon a new inhibitor of monoamine oxidase in brain tissue, Biochem. Pharmacol. 17 (1968) 1285-1297.

[47] J. Hirvonen, M. Kailajarvi, T. Haltia, S. Koskimies, K. Nagren, P. Virsu, V. Oikonen, H. Sipila, P. Ruokoniemi, K. Virtanen, M. Scheinin, J.O. Rinne, Assessment of MAO-B occupancy in the brain with PET and [C-11]-L-Deprenyl-D-2: a dose-finding study with a novel MAO-B Inhibitor, EVT 301, Clin. Pharmacol. Ther. 85 (2009) 506-512.

[48] M. Naoi, P. Riederer, W. Maruyama, Modulation of monoamine oxidase (MAO) expression in 
neuropsychiatric disorders: genetic and environmental factors involved in type A MAO expression, J. Neural. Transm. (Vienna) 123 (2016) 91-106.

[49] M.B.H. Youdim, Y.S. Bakhle, Monoamine oxidase: isoforms and inhibitors in Parkinson's disease and depressive illness, Br. J. Pharmacol. 147 (2006) S287-S296.

[50] P. Riederer, W. Danielczyk, E. Grunblatt, Monoamine oxidase-B inhibition in Alzheimer's disease, Neurotoxicology 25 (2004) 271-277.

[51] F. Caraci, A. Copani, F. Nicoletti, F. Drago, Depression and Alzheimer's disease: neurobiological links and common pharmacological targets, Eur. J. Pharmacol. 626 (2010) 64-71.

[52] Z.P. Sang, W.L. Pan, K.R. Wang, Q.G. Ma, L.T. Yu, W.M. Liu, Design, synthesis and biological evaluation of 3,4-dihydro-2(1H)-quinoline-O-alkylamine derivatives as new multipotent cholinesterase/monoamine oxidase inhibitors for the treatment of Alzheimer's disease, Bioorg. Med. Chem. 25 (2017) 3006-3017.

[53] Y.X. Xu, J. Zhang, H. Wang, F. Mao, K.T. Bao, W.W. Liu, J. Zhu, X.K. Li, H.Y. Zhang, J. Li, Rational Design of novel selective dual-target inhibitors of acetylcholinesterase and monoamine oxidase $\mathrm{B}$ as potential anti-Alzheimer's disease agents, ACS. Chem. Neurosci. 10 (2019) 482-496.

[54] O. Weinreb, T. Amit, O. Bar-Am, M.B.H. Youdim, Neuroprotective effects of multifaceted hybrid agents targeting MAO, cholinesterase, iron and $\beta$-amyloid in ageing and Alzheimer's disease, Br. J. Pharmacol. 173 (2016) 2080-2094.

[55] M. Rosini, E. Simoni, R. Caporaso, A. Minarini, Multitarget strategies in Alzheimer's disease: benefits and challenges on the road to therapeutics, Future Med. Chem. 8 (2016) 697-711.

[56] I. Bolea, J. Juarez-Jimenez, C. de los Rios, M. Chioua, R. Pouplana, F.J. Luque, M. Unzeta, J. Marco-Contelles, A. Samadi, Synthesis, biological evaluation, and molecular modeling of donepezil and

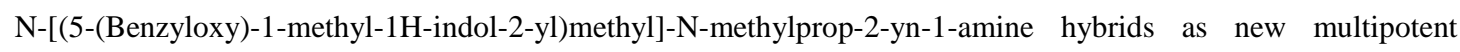
cholinesterase/monoamine oxidase inhibitors for the treatment of Alzheimer's disease, J. Med. Chem. 54 (2011) $8251-8270$.

[57] V. Perez, J.L. Marco, E. Fernandez-Alvarez, M. Unzeta, Relevance of benzyloxy group in 2-indolyl methylamines in the selective MAO-B inhibition, Br. J. Pharmacol. 127 (1999) 869-876.

[58] L. Wang, G. Esteban, M. Ojima, O.M. Bautista-Aguilera, T. Inokuchi, I. Moraleda, I. Iriepa, A. Samadi, M.B.H. Youdim, A. Romero, E. Soriano, R. Herrero, A.P.F. Fernandez, Ricardo-Martinez-Murillo, J. Marco-Contelles, M. Unzeta, Donepezil + propargylamine +8 -hydroxyquinoline hybrids as new multifunctional metal-chelators, ChE and MAO inhibitors for the potential treatment of Alzheimer's disease, Eur. J. Med. Chem. 
80 (2014) 543-561.

[59] Y. Avramovich-Tirosh, T. Amit, O. Bar-Am, H.L. Zheng, M. Fridkin, M.B.H. Youdim, Therapeutic targets and potential of the novel brain-permeable multifunctional iron chelator-monoamine oxidase inhibitor drug, M-30, for the treatment of Alzheimer's disease, J. Neurochem. 100 (2007) 490-502.

[60] M.Y. Wu, G. Esteban, S. Brogi, M. Shionoya, L. Wang, G. Campiani, M. Unzeta, T. Inokuchi, S. Butini, J. Marco-Contelles, Donepezil-like multifunctional agents: design, synthesis, molecular modeling and biological evaluation, Eur. J. Med. Chem. 121 (2016) 864-879.

[61] M. Estrada, C. Herrera-Arozamena, C. Perez, D. Vina, A. Romero, J.A. Morales-Garcia, A. Perez-Castillo, M.I. Rodriguez-Franco, New cinnamic - N-benzylpiperidine and cinnamic - N,N-dibenzyl(N-methyl)amine hybrids as Alzheimer-directed multitarget drugs with antioxidant, cholinergic, neuroprotective and neurogenic properties, Eur. J. Med. Chem. 121 (2016) 376-386.

[62] S. Carradori, R. Silvestri, New frontiers in selective human MAO-B inhibitors, J. Med. Chem. 58 (2015) 6717-6732.

[63] C.J. Lu, Q. Zhou, J. Yan, Z.Y. Du, L. Huang, X.S. Li, A novel series of tacrine-selegiline hybrids with cholinesterase and monoamine oxidase inhibition activities for the treatment of Alzheimer's disease, Eur. J. Med. Chem. 62 (2013) 745-753.

[64] Y. Sun, J.W. Chen, X.M. Chen, L. Huang, X.S. Li, Inhibition of cholinesterase and monoamine oxidase-B activity by Tacrine-Homoisoflavonoid hybrids, Bioorg. Med. Chem. 21 (2013) 7406-7417.

[65] N. Desideri, A. Bolasco, R. Fioravanti, L.P. Monaco, F. Orallo, M. Yanez, F. Ortuso, S. Acaro, Homoisoflavonoids: natural scaffolds with potent and selective monoamine oxidase-B inhibition properties, J. Med. Chem. 54 (2011) 2155-2164.

[66] Y.L. Wang, Y. Sun, Y.Y. Guo, Z.C. Wang, L. Huang, X.S. Li, Dual functional cholinesterase and MAO inhibitors for the treatment of Alzheimer's disease: synthesis, pharmacological analysis and molecular modeling of homoisoflavonoid derivatives, J. Enzyme Inhib. Med. Chem. 31 (2016) 389-397.

[67] O. Benek, O. Soukup, M. Pasdiorova, L. Hroch, V. Sepsova, P. Jost, M. Hrabinova, D. Jun, K. Kuca, D. Zala, R.R. Ramsay, J. Marco-Contelles, K. Musilek, Design, Synthesis and in vitro evaluation of indolotacrine analogues as multitarget-directed ligands for the treatment of Alzheimer's disease, ChemMedChem. 11 (2016) 1264-1269.

[68] Y.X. Xu, H. Wang, X.K. Li, S.N. Dong, W.W. Liu, Q. Gong, T.D. Wang, Y. Tang, J. Zhu, J. Li, H.Y. Zhang, F. Mao, Discovery of novel propargylamine-modified 4-aminoalkyl imidazole substituted pyrimidinylthiourea 
derivatives as multifunctional agents for the treatment of Alzheimer's disease, Eur. J. Med. Chem. 143 (2018) $33-47$.

[69] T. Storr, K.H. Thompson, C. Orvig, Design of targeting ligands in medicinal inorganic chemistry, Chem. Soc. Rev. 35 (2006) 534-544.

[70] K.J. Barnham, C.L. Masters, A.I. Bush, Neurodegenerative diseases and oxidative stress, Nat. Rev. Drug Discov. 3 (2004) 205-214.

[71] K.P. Kepp, Bioinorganic chemistry of Alzheimer's disease, Chem. Rev. 112 (2012) 5193-5239.

[72] X.K. Li, H. Wang, Z.Y. Lu, X.Y. Zheng, W. Ni, J. Zhu, Y. Fu, F.L. Lian, N.X. Zhang, J. Li, H.Y. Zhang, F. Mao, Development of multifunctional pyrimidinylthiourea derivatives as potential anti-Alzheimer agents, J. Med. Chem. 59 (2016) 8326-8344.

[73] N. Braidy, A. Poljak, C. Marjo, H. Rutlidge, A. Rich, T. Jayasena, N.C. Inestrosa, P. Sachdev, Metal and complementary molecular bioimaging in Alzheimer's disease, Front. Aging Neurosci. 6 (2014) 138.

[74] Z.R. Wang, J.H. Hu, X.P. Yang, X. Feng, X.S. Li, L. Huang, A.S.C. Chan, Design, synthesis, and evaluation of orally bioavailable quinoline-indole derivatives as innovative multitarget-directed ligands: promotion of cell proliferation in the adult murine hippocampus for the treatment of Alzheimer's disease, J. Med. Chem. 61 (2018) 1871-1894.

[75] P.J. Crouch, K.J. Barnham, Therapeutic redistribution of metal ions to treat Alzheimer's disease, Acc. Chem. Res. 45 (2012) 1604-1611.

[76] M.I. Fernandez-Bachiller, C. Perez, G.C. Gonzalez-Munoz, S. Conde, M.G. Lopez, M. Villarroya, A.G. Garcia, M.I. Rodriguez-Franco, Novel tacrine-8-Hydroxyquinoline hybrids as multifunctional agents for the treatment of Alzheimer's disease, with neuroprotective, cholinergic, antioxidant, and copper-complexing properties, J. Med. Chem. 53 (2010) 4927-4937.

[77] S.Y. Li, X.B. Wang, S.S. Xie, N. Jiang, K.D.G. Wang, H.Q. Yao, H.B. Sun, L.Y. Kong, Multifunctional tacrine flavonoid hybrids with cholinergic, $\beta$-amyloid-reducing, and metal chelating properties for the treatment of Alzheimer's disease, Eur. J. Med. Chem. 69 (2013) 632-646.

[78] S.S. Xie, X.B. Wang, J.Y. Li, L. Yang, L.Y. Kong, Design, synthesis and evaluation of novel tacrine coumarin hybrids as multifunctional cholinesterase inhibitors against Alzheimer's disease, Eur. J. Med. Chem. 64 (2013) 540-553.

[79] C. Bruhlmann, F. Ooms, P.A. Carrupt, B. Testa, M. Catto, F. Leonetti, C. Altomare, A. Carotti, Coumarins derivatives as dual inhibitors of acetylcholinesterase and monoamine oxidase, J. Med. Chem. 44 (2001) 
3195-3198.

[80] Q. Liu, X.M. Qiang, Y. Li, Z.P. Sang, Y.X. Li, Z.H. Tan, Y. Deng, Design, synthesis and evaluation of chromone-2-carboxamido-alkylbenzylamines as multifunctional agents for the treatment of Alzheimer's disease, Bioorg. Med. Chem. 23 (2015) 911-923.

[81] J. Yan, J.H. Hu, A.Q. Liu, L. He, X.S. Li, H. Wei, Design, synthesis, and evaluation of multitarget-directed ligands against Alzheimer's disease based on the fusion of donepezil and curcumin, Bioorg. Med. Chem. 25 (2017) 2946-2955.

[82] E. Shimizu, Y.P. Tang, C. Rampon, J.Z. Tsien, NMDA receptor-dependent synaptic reinforcement as a crucial process for memory consolidation, Science 290 (2000) 1170-1174.

[83] H. Geerts, G. Grossberg, Pharmacology of acetylcholinesterase inhibitors and N-methyl-D-aspartate receptors for combination therapy in the treatment of Alzheimer's disease, J. Clin. Pharmacol. 46 (2006) 8S-16S.

[84] C.G. Parsons, W. Danysz, A. Dekundy, I. Pulte, Memantine and cholinesterase inhibitors: complementary mechanisms in the treatment of Alzheimer's disease, Neurotox. Res. 24 (2013) 358-369.

[85] G.L. Wenk, W. Danysz, S.L. Mobley, Investigations of neurotoxicity and neuroprotection within the nucleus basalis of the rat, Brain Res. 655 (1994) 7-11.

[86] M. Rosini, E. Simoni, A. Minarini, C. Melchiorre, Multi-target design strategies in the context of Alzheimer's disease: acetylcholinesterase inhibition and NMDA receptor antagonism as the driving forces, Neurochem. Res. 39 (2014) 1914-1923.

[87] M. Rosini, E. Simoni, M. Bartolini, A. Cavalli, L. Ceccarini, N. Pascu, D.W. McClymont, A. Tarozzi, M.L. Bolognesi, A. Minarini, V. Tumiatti, V. Andrisano, I.R. Mellor, C. Melchiorre, Inhibition of acetylcholinesterase, $\beta$-amyloid aggregation, and NMDA receptors in Alzheimer's disease: A promising direction for the multi-target-directed ligands gold rush, J. Med. Chem. 51 (2008) 4381-4384.

[88] E. Simoni, S. Daniele, G. Bottegoni, D. Pizzirani, M.L. Trincavelli, L. Goldoni, G. Tarozzo, A. Reggiani, C. Martini, D. Piomelli, C. Melchiorre, M. Rosini, A. Cavalli, Combining galantamine and memantine in multitargeted, new chemical entities potentially useful in Alzheimer's disease, J. Med. Chem. 55 (2012) 9708-9721.

[89] M. Rosini, E. Simoni, M. Bartolini, E. Soriano, J. Marco-Contelles, V. Andrisano, B. Monti, M. Windisch, B. Hutter-Paier, D.W. McClymont, I.R. Mellor, M.L. Bolognesi, The bivalent ligand approach as a tool for improving the in vitro anti-Alzheimer multitarget profile of dimebon, ChemMedChem. 8 (2013) 1276-1281.

[90] G.F. Makhaeva, S.V. Lushchekina, N.P. Boltneva, V.B. Sokolov, V.V. Grigoriev, O.G. Serebryakova, E.A. 
Vikhareva, A.Y. Aksinenko, G.E. Barreto, G. Aliev, S.O. Bachurin, Conjugates of $\gamma$-carbolines and phenothiazine as new selective inhibitors of butyrylcholinesterase and blockers of NMDA receptors for Alzheimer Disease, Sci. Rep. 5 (2015) 13164.

[91] J.J. Rodriguez, H.N. Noristani, A. Verkhratsky, The serotonergic system in ageing and Alzheimer's disease, Prog. Neurobiol. 99 (2012) 15-41.

[92] J. Savitz, I. Lucki, W.C. Drevets, 5-HT1A receptor function in major depressive disorder, Prog. Neurobiol. 88 (2009) 17-31.

[93] A. Mowla, M. Mosavinasab, H. Haghshenas, A. Borhani-Haghighi, Does serotonin augmentation have any effect on cognition and activities of daily living in Alzheimer's dementia? A double-blind, placebo-controlled clinical trial, J. Clin. Psychopharmacol. 27 (2007) 484-487.

[94] M. Matsumoto, H. Togashi, K. Morio, K. Ueno, S. Ohashi, T. Kojima, M. Yoshioka, Evidence for involvement of central 5-HT4 receptors in cholinergic function associated with cognitive processes: behavioral, electrophysiological, and neurochemical studies, J. Pharmacol. Exp. Ther. 296 (2001) 676-682.

[95] S. Cho, Y. Hu, Activation of 5-HT4 receptors inhibits secretion of $\beta$-amyloid peptides and increases neuronal survival, Exp. Neurol. 203 (2007) 274-278.

[96] F. Lezoualc'h, 5-HT4 receptor and Alzheimer's disease: The amyloid connection, Exp. Neurol. 205 (2007) $325-329$.

[97] N. Upton, T.T. Chuang, A.J. Hunter, D.J. Virley, 5-HT6 receptor antagonists as novel cognitive enhancing agents for Alzheimer's disease, Neurotherapeutics 5 (2008) 458-469.

[98] T. Freret, V. Bouet, A. Quiedeville, G. Nee, P. Dallemagne, C. Rochais, M. Boulouard, Synergistic effect of acetylcholinesterase inhibition (donepezil) and 5-HT4 receptor activation (RS67333) on object recognition in mice, Behav. Brain Res. 230 (2012) 304-308.

[99] C. Lecoutey, D. Hedoua, T. Freret, P. Giannoni, F. Gaven, M. Since, V. Bouet, C. Ballandonne, S. Corvaisier, A.M. Freon, S. Mignani, T. Cresteil, M. Boulouard, S. Claeysen, C. Rochais, P. Dallemagne, Design of donecopride, a dual serotonin subtype 4 receptor agonist/acetylcholinesterase inhibitor with potential interest for Alzheimer's disease treatment, Proc. Natl. Acad. Sci. U. S. A. 111 (2014) E3825-E3830.

[100] C. Lecoutey, C. Rochais, D. Genest, S. Butt-Gueulle, C. Ballandonne, S. Corvaisier, F. Dial, A. Lepailleur, J.S.D. Santos, P. Dallemagne, Synthesis of dual AChE/5-HT4 receptor multi-target directed ligands, Medchemcomm. 3 (2012) 627-634.

[101] C. Rochais, C. Lecoutey, F. Gaven, P. Giannoni, K. Hamidouche, D. Hedou, E. Dubost, D. Genest, S. 
Yahiaoui, T. Freret, V. Bouet, F. Dauphin, J.S.D. Santos, C. Ballandonne, S. Corvaisier, A. Malzert-Freon, R. Legay, M. Boulouard, S. Claeysen, P. Dallemagne, Novel multitarget-directed ligands (MTDLs) with acetylcholinesterase (AChE) inhibitory and serotonergic subtype 4 receptor (5-HT4R) agonist activities as potential agents against Alzheimer's disease: the design of donecopride, J. Med. Chem. 58 (2015) 3172-3187.

[102] W.W. Liu, H. Wang, X.K. Li, Y.X. Xu, J. Zhang, W. Wang, Q. Gong, X.X. Qiu, J. Zhu, F. Mao, H.Y. Zhang, J. $\mathrm{Li}$, Design, synthesis and evaluation of vilazodone-tacrine hybrids as multitarget-directed ligands against depression with cognitive impairment, Bioorg. Med. Chem. 26 (2018) 3117-3125.

[103] P. Panula, P.L. Chazot, M. Cowart, R. Gutzmer, R. Leurs, W.L.S. Liu, H. Stark, R.L. Thurmond, H.L. Haas, International union of basic and clinical pharmacology. XCVIII. Histamine receptors, Pharmacol. Rev. 67 (2015) 601-655.

[104] G.M. Haig, Y. Pritchett, A. Meier, A.A. Othman, C. Hall, L.M. Gault, R.A. Lenz, A randomized study of H3 antagonist ABT-288 in mild-to-moderate Alzheimer's dementia, J. Alzheimers Dis. 42 (2014) 959-971.

[105] M. Kubo, T. Kishi, S. Matsunaga, N. Iwata, Histamine H3 receptor antagonists for Alzheimer's disease: a systematic review and meta-analysis of randomized placebo-controlled trials, J. Alzheimers Dis. 48 (2015) 667-671.

[106] W.H. Huang, L. Tang, Y. Shi, S.F. Huang, L. Xu, R. Sheng, P. Wu, J. Li, N.M. Zhou, Y.Z. Hu, Searching for the multi-target-directed ligands against Alzheimer's disease: discovery of quinoxaline-based hybrid compounds with AChE, H3R and BACE 1 inhibitory activities, Bioorg. Med. Chem. 19 (2011) 7158-7167.

[107] J.A. Beavo, Cyclic nucleotide phosphodiesterases: functional implications of multiple isoforms, Physiol. Rev. 75 (1995) 725-748.

[108] A.T. Bender, J.A. Beavo, Cyclic nucleotide phosphodiesterases: molecular regulation to clinical use, Pharmacol. Rev. 58 (2006) 488-520.

[109] P.R.A. Heckman, C. Wouters, J. Prickaerts, Phosphodiesterase inhibitors as a target for cognition enhancement in aging and Alzheimer's disease: a translational overview, Curr. Pharm. Des. 21 (2015) 317-331.

[110] Z.H. Qin, Modulating nitric oxide signaling in the CNS for Alzheimer's disease therapy, Future Med. Chem. 5 (2013) 1451-1468.

[111] Y.F. Li, Y.F. Cheng, Y. Huang, M. Conti, S.P. Wilson, J.M. O'Donnell, H.T. Zhang, Phosphodiesterase-4D knock-out and RNA interference-mediated knock-down enhance memory and increase hippocampal neurogenesis via increased cAMP signaling, J. Neurosci. 31 (2011) 172-183.

[112] P.R.A. Heckman, A. Blokland, J. Ramaekers, J. Prickaerts, PDE and cognitive processing: beyond the 
memory domain, Neurobiol. Learn. Mem. 119 (2015) 108-122.

[113] C. Garcia-Barroso, A. Ricobaraza, M. Pascual-Lucas, N. Unceta, A.J. Rico, M.A. Goicolea, J. Salles, J.L. Lanciego, J. Oyarzabal, R. Franco, M. Cuadrado-Tejedor, A. Garcia-Osta, Tadalafil crosses the blood-brain barrier and reverses cognitive dysfunction in a mouse model of AD, Neuropharmacology 64 (2013) 114-123.

[114] F. Mao, H. Wang, W. Ni, X. Zheng, M.J. Wang, K.T. Bao, D.Z. Ling, X.K. Li, Y.X. Xu, H.Y. Zhang, J. Li, Design, synthesis, and biological evaluation of orally available first-generation dual-target selective inhibitors of acetylcholinesterase (AChE) and phosphodiesterase 5 (PDE5) for the treatment of Alzheimer's disease, ACS. Chem. Neurosci. 9 (2018) 328-345.

[115] S.H. Francis, M.A. Blount, J.D. Corbin, Mammalian cyclic nucleotide phosphodiesterases: molecular mechanisms and physiological functions, Physiol. Rev. 91 (2011) 651-690.

[116] F. Prati, G. Bottegoni, M.L. Bolognesi, A. Cavalli, BACE-1 inhibitors: from recent single-target molecules to multitarget compounds for Alzheimer's disease, J. Med. Chem. 61 (2018) 619-637.

[117] F. Prati, A. De Simone, P. Bisignano, A. Armirotti, M. Summa, D. Pizzirani, R. Scarpelli, D.I. Perez, V. Andrisano, A. Perez-Castillo, B. Monti, F. Massenzio, L. Polito, M. Racchi, A.D. Favia, G. Bottegoni, A. Martinez, M.L. Bolognesi, A. Cavalli, Multitarget drug discovery for Alzheimer's disease: triazinones as BACE-1 and GSK-3 $\beta$ inhibitors, Angew. Chem. Int. Ed. Engl. 54 (2015) 1578-1582.

[118] R.M.C. Di Martino, A. De Simone, V. Andrisano, P. Bisignano, A. Bisi, S. Gobbi, A. Rampa, R. Fato, C. Bergamini, D.I. Perez, A. Martinez, G. Bottegoni, A. CavaIli, F. Belluti, Versatility of the curcumin scaffold: discovery of potent and balanced dual BACE-1 and GSK-3 $\beta$ inhibitors, J. Med. Chem. 59 (2016) 531-544.

[119] S. Prasad, S.C. Gupta, A.K. Tyagi, B.B. Aggarwal, Curcumin, a component of golden spice: From bedside to bench and back, Biotechnol. Adv. 32 (2014) 1053-1064.

[120] S.S. Xie, J. Chen, X.R. Li, T. Su, Y.L. Wang, Z.R. Wang, L. Huang, X.S. Li, Synthesis and evaluation of selegiline derivatives as monoamine oxidase inhibitor, antioxidant and metal chelator against Alzheimer's disease, Bioorg. Med. Chem. 23 (2015) 3722-3729.

[121] T. Su, T.H. Zhang, S.S. Xie, J. Yan, Y. Wu, X.S. Li, L. Huang, H.B. Luo, Discovery of novel PDE9 inhibitors capable of inhibiting $A \beta$ aggregation as potential candidates for the treatment of Alzheimer's disease, Sci. Rep. 6 (2016) 21826.

[122] Z.R. Wang, Y.L. Wang, B. Wang, W.R. Li, L. Huang, X.S. Li, Design, synthesis, and evaluation of orally available clioquinol-moracin $\mathrm{M}$ hybrids as multitarget-directed ligands for cognitive improvement in a rat model of neurodegeneration in Alzheimer's disease, J. Med. Chem. 58 (2015) 8616-8637. 
[123] A.S. Cornec, L. Monti, J. Kovalevich, V. Makani, M.J. James, K.G. Vijayendran, K. Oukoloff, Y.M. Yao, V.M.Y. Lee, J.Q. Trojanowski, A.B. Smith, K.R. Brunden, C. Ballatore, Multitargeted imidazoles: potential therapeutic leads for Alzheimer's and other neurodegenerative diseases, J. Med. Chem. 60 (2017) 5120-5145.

[124] Y. Xia, R. Liu, R. Chen, Q. Tian, K. Zeng, J. Hu, X. Liu, Q. Wang, P. Wang, X.C. Wang, J.Z. Wang. Novel multipotent AChEI-CCB attenuates hyperhomocysteinemia-induced memory deficits and neuropathologies in rats, J. Alzheimers Dis. 42 (2014) 1029-1039.

[125] http://www.chictr.org.cn/showproj.aspx?proj=27354\&from=singlemessage\&isappinstalled=0

[126] H. Yao, J.K. Liu, S.T. Xu, Z.Y. Zhu, J.Y. Xu, The structural modification of natural products for novel drug discovery, Expert. Opin. Drug Discov. 12 (2017) 121-140. 